\title{
Correlation of the use of computers by education faculty with national standards for preservice students
}

\author{
Robin T. Twery \\ West Virginia University
}

Follow this and additional works at: https://researchrepository.wvu.edu/etd

\section{Recommended Citation}

Twery, Robin T., "Correlation of the use of computers by education faculty with national standards for preservice students" (2003). Graduate Theses, Dissertations, and Problem Reports. 2489.

https://researchrepository.wvu.edu/etd/2489

This Dissertation is protected by copyright and/or related rights. It has been brought to you by the The Research Repository @ WVU with permission from the rights-holder(s). You are free to use this Dissertation in any way that is permitted by the copyright and related rights legislation that applies to your use. For other uses you must obtain permission from the rights-holder(s) directly, unless additional rights are indicated by a Creative Commons license in the record and/ or on the work itself. This Dissertation has been accepted for inclusion in WVU Graduate Theses, Dissertations, and Problem Reports collection by an authorized administrator of The Research Repository @ WVU.

For more information, please contact researchrepository@mail.wvu.edu. 
Correlation of the use of computers by education faculty with national standards for preservice students

\title{
Robin Twery
}

\author{
Dissertation submitted to the \\ College of Human Resources and Education \\ at West Virginia University \\ in partial fulfillment of the requirements \\ for the degree of
}

\author{
Doctor of Education \\ in \\ Technology Education
}

George Maughan, Ed.D., Chair

David McCrory, Ph.D. Anne Nardi, Ph.D.

Barbara Ludlow, Ed.D. Sue Day-Perroots, Ed. D

\section{Advanced Educational Studies \\ Morgantown, West Virginia 2003}




\begin{abstract}
Correlation of the Use of Computers by Education Faculty with National Standards for Preservice Students
\end{abstract}

\begin{abstract}
Robin T. Twery
The purpose of this research study was to provide information to faculty, administrators and state departments of education about the level of integration of computer technology into teacher education programs. The stated problem of this research was to determine the correlation of the use of computers by education faculty with national standards for preservice teachers. A review of the literature identified the continuing growth of computer use and a growing acceptance of national standards for computer literacy in K12 and higher education settings. To determine the extent of computer use among education faculty, a three-part survey was developed. It including a Likert-type scale based on technology-use standards developed by the International Society for Technology in Education, questions regarding teaching experience and computer skills, and open-ended questions allowing for input on support for or obstacles to the integration of technology in the participating institutions. The study included only programs in Vermont which certified students to teach in K-12 settings. Surveys were sent to private and state institutions, with a total return rate of $46 \%$.
\end{abstract}

Once data gathering was completed, analysis was done using JMPin, a version of SAS. Data were analyzed using descriptive statistics, and significance was tested using Pearson's product-moment correlation for continuous data and chi-squares for ordinal data. Faculty were asked to what degree they modeled and/or required the specific standards for preservice teachers. Of those who responded, $83 \%$ reported modeling the standards to a low to moderate degree, while $90 \%$ reported requiring the standards at a low to moderate degree. Analysis of the correlation between teaching experience and the modeling and requiring of the standards showed little significance. There was a positive correlation to the faculty's rating of their own computer skills. The open-ended questions brought forth comments including appreciation of strong institutional support, and concerns about technology training and time to use the skills learned. The results indicated that there were faculty at all the colleges who were modeling and requiring technology skills, which are now being required for certification in Vermont and 42 other states. 


\section{DEDICATION}

This work is dedicated to my father, who inspired me early on to have an interest in the ways in which things worked, and to enjoy the process of learning about the world around me. 


\section{ACKNOWLEDGMENT}

While completing a project of this complexity I was lucky to receive assistance from many people. I would like to recognize those whose help was crucial.

As part of my program I wound up taking courses with all four of the faculty in the Technology Education Department. Along with my committee members, Drs. Pytlik and Wells opened my eyes to the range of study which could be accomplished in the field through their knowledge and interest in their courses

I moved away from campus once my coursework was finished. Even though we could not meet in person, my committee members Dr. McCrory, Dr. Nardi, Dr. Ludlow and Dr. Day-Perroots continued to offer resources and comments which proved beneficial. I would also like to acknowledge the assistance with statistics which I received from the late Dr. Paterson, who had been an original member of my committee.

The chair of my committee, Dr. George Maughan, remained upbeat and encouraging throughout the process. His questions and comments help me remain focused on the task and his advice was beneficial to the completion of my project.

During the entire project I could count on Carol Spiroff, the department's Administrative Associate, to help me with procedures and paperwork, acting as my proxy when forms needed to be signed and delivered. I could also count on Carol to offer information I needed about the steps to take to meet the needs of the university, to help me stay in touch with the faculty while I was so far off campus, and for a friendly voice on the other end of the telephone.

My friends Marla Emery and Jim Palmer, were also important to me. Marla, having recently completed her own doctorate, was able to commiserate with me and support my efforts. Jim, having been an advisor to other students, also offered encouragement along with resources for the statistical assessments I needed to complete.

My mother Helen Turer and brother Richard Turer maintained confidence in my ability to complete the task, and bolstered my spirits when they flagged.

My daughter Naomi was enthusiastic about my decision to embark on a major research project, even though it meant I had less time to spend on home tasks. She empathized with my struggles on returning to the classroom as student instead of teacher and later helped me proofread the data I had entered and the documents I produced.

Throughout the entire, long process my husband, Mark Twery, was my advocate and my proponent. He not only reassured me when I felt overwhelmed by the task, but was a patient listener, often reminding me that perseverance was key to finishing a major research project. His advice on formats and statistics were instrumental to my success, but it was his emotional strength and his belief in me which I value most. 


\section{Table of Contents}

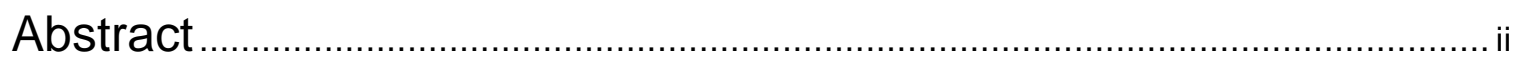

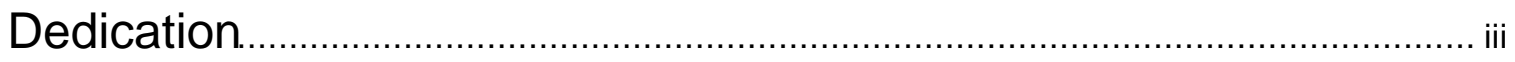

Acknowledgment ...................................................................................................

List of Tables ...............................................................................................................

\section{Chapter One - Introduction}

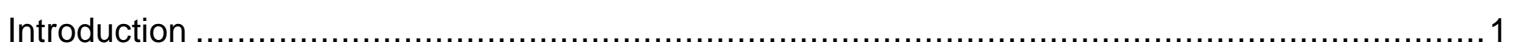

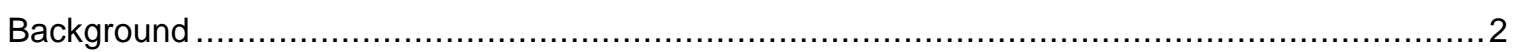

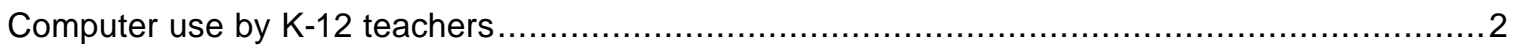

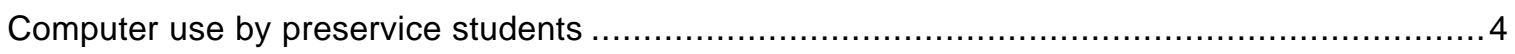

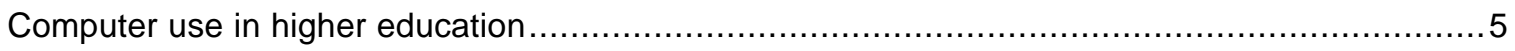

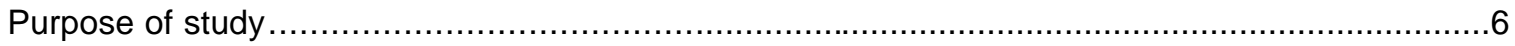

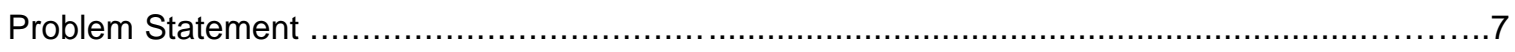

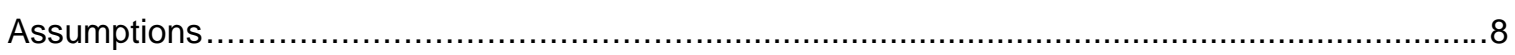

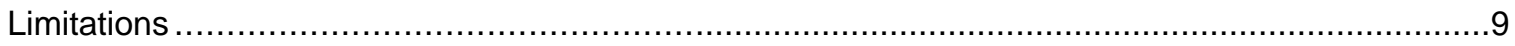

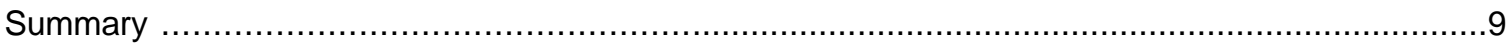

\section{Chapter Two - Review of Literature}

Introduction

Computer use by $\mathrm{K}-12$ teachers.

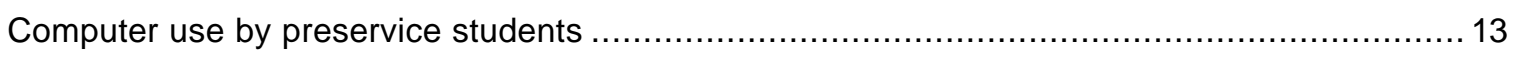

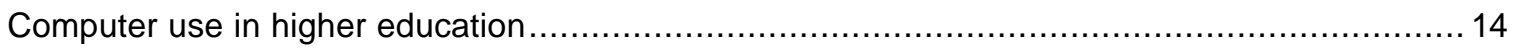

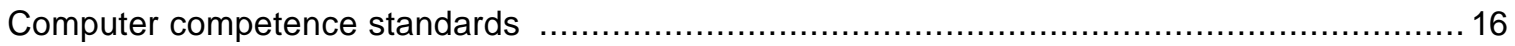




\section{Chapter Three - Research Methods}

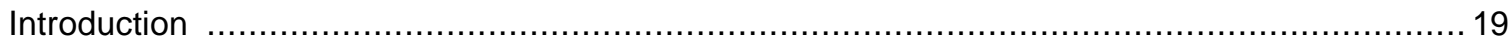

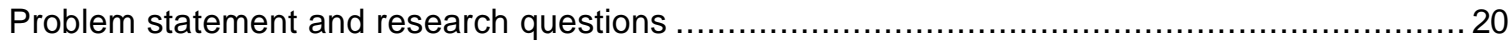

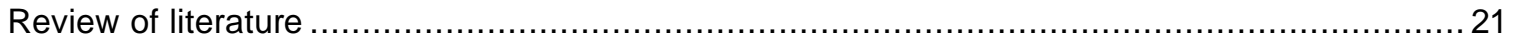

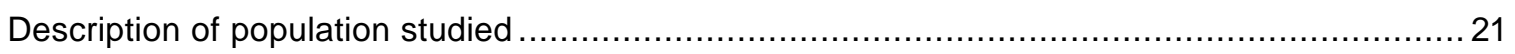

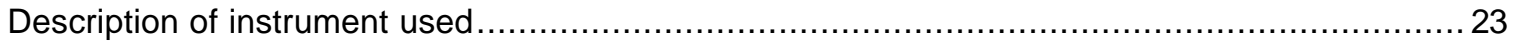

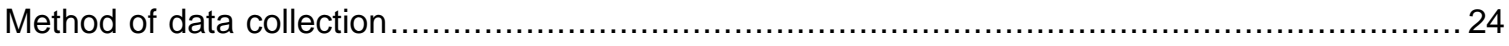

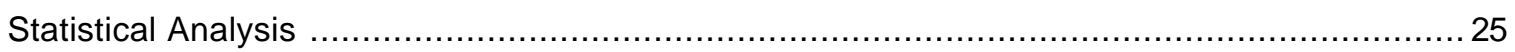

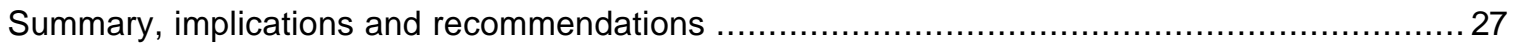

\section{Chapter Four - Research Findings}

Introduction

Survey ,Part I Standards

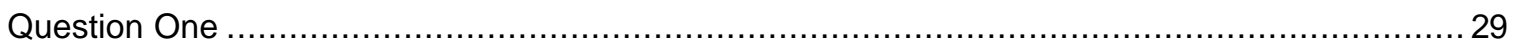

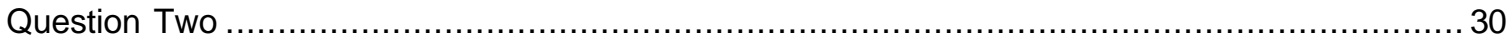

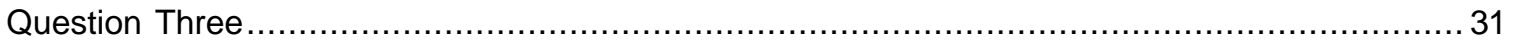

Survey, Part II Demographic questions

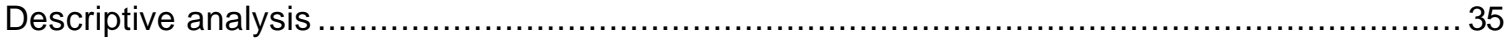

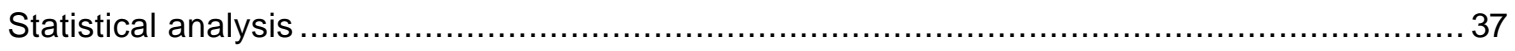

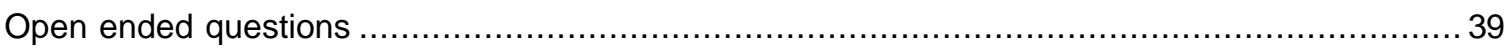




\section{Chapter Five - Summary, Implications and Recommendations}

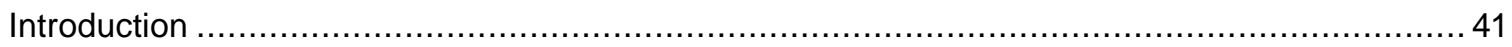

Survey Part I

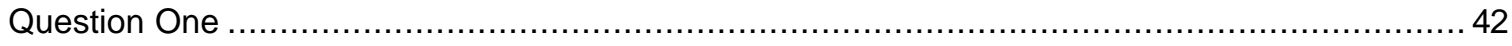

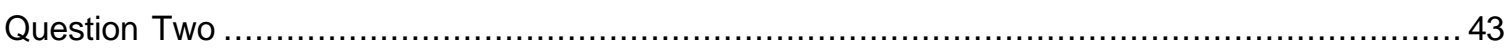

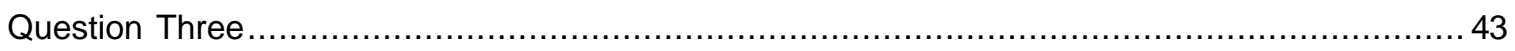

Survey, Part II

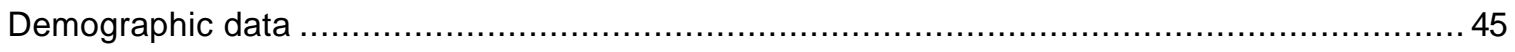

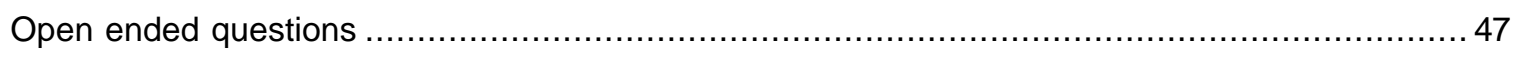

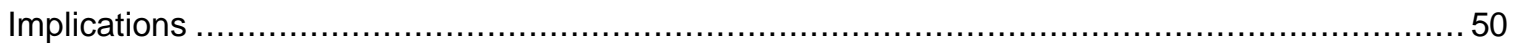

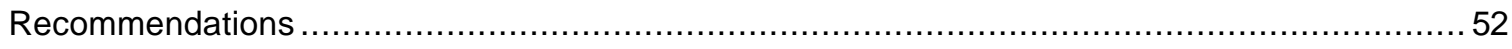

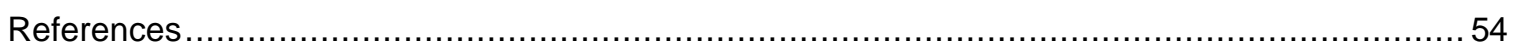

\section{Appendices}

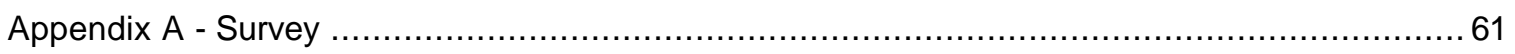

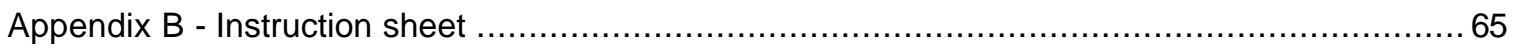

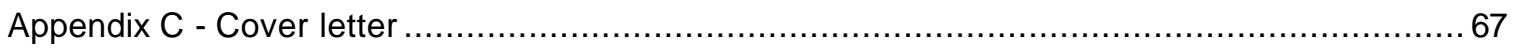

Appendix D - Email reminder reminder-second mailing ............................................ 68

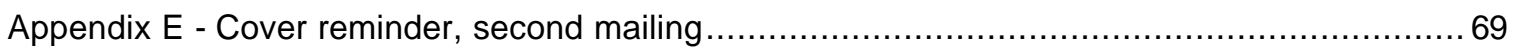

Appendix F - Results of t-test and Pearson correlations, standards required vs standards

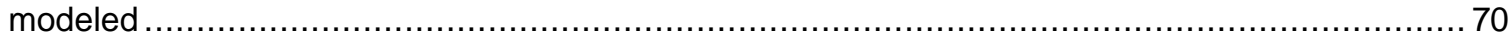

Appendix G - Pearson correlations for demographic questions by standards modeled.............. 72

Appendix $\mathrm{H}$ - Pearson correlations for demographic questions by standards required .............. 74

Appendix I - Contingency tables significance for standards modeled by demographic questions 76 Appendix $\mathrm{J}$ - Contingency tables significance for standards required by

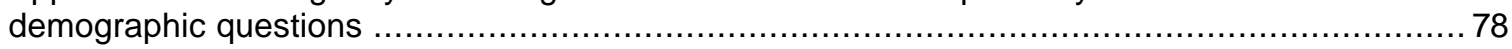

Appendix K - Pearson correlations for demographic questions by categories ....................... 80

Appendix L - Contingency tables of demographic questions by categories ........................ 81

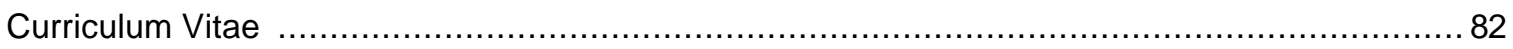




\section{List of Tables}

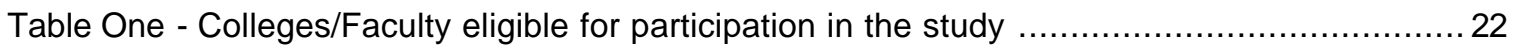

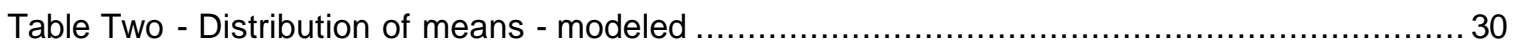

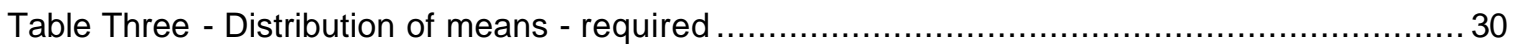

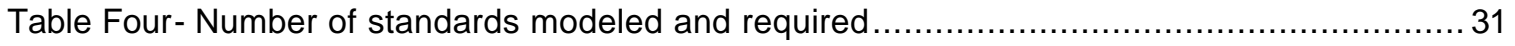

Table Five - Standards exhibiting differences between

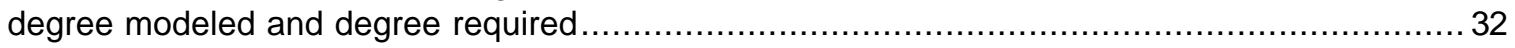

Table Six - ISTE broad categories for the

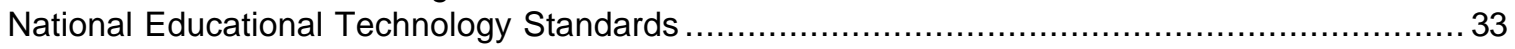

Table Seven - Percentage of standards modeled, by category ....................................... 34

Table Eight - Percentage of standards required, by category ........................................ 35

Table Nine - Results of contingency analysis on standards, by demographic questions ............38 
Chapter One

Introduction

Throughout history societies have grown and changed. Educational systems have likewise gone through alterations and modifications. Although the purposes of education may have altered, the overall role of education has been to increase and enhance the abilities of the student. Teachers help students build skills, learn new facts, and gain an understanding of the world around them.

A variety of tools have been available to the teacher, from chalk and slates to computers and multimedia presentations. Most current studies of these tools in K-12 settings concentrate on the use of telecommunication technologies, specifically computers and the Internet. Many studies show increases in the availability of these tools to teachers, but a less dramatic growth in their use. There has been an increase of reports on the access college faculty have to communication technologies, either throughout the institution or in specific disciplines. Studies also discuss how these tools are being used and by whom.

Schools of education, being the very places which prepare new teachers to use these technologies in K-12 settings, should be in the forefront of the most effective use of communication technology. A number of studies have noted that colleges have adopted three approaches to the use of technology in education (Halpin, 1999; Vagle,1995). Either: 1) students will learn what is needed on their own, 2) students will learn in a separate laboratory or a stand-alone technology use class, and/or 3) students will learn through taking classes in which technology is integrated by many faculty members in many classes. The latter was found to be more effective in helping preservice students see the value of using various types of communication technologies in their professional lives (Oppong, Gootman, \& Beckmann, 1997).

The primary concern of this study is to determine the degree to which education faculty model the technologies which pre-service students will use in their careers and to what degree they require their students to exhibit skills in those technologies. In order to evaluate the degree of modeling and requiring, higher education faculty members whose responsibilities include teaching education courses will be asked to report on their own and their students' integration of technology into the curriculum. 


\section{Background}

There is a continuing trend in education toward increasing the use of a variety of communication technologies. As early as 1995, Neff found that "This is a time of transition from blackboard and chalk and use of the overhead projector to the generalpurpose projection system capable of handling all formats of digital and analog media and the classroom where there is a networked computer at each seat." (p. 1). Educators, in all levels, must deal with these changes - they must not only prepare students but also must keep up with changes in the way in which teaching can be done. The background information presented will address computer use by teachers in K-12 settings, preservice education students, and higher education faculty involved in teacher preparation coursework, as well as the issue of standards in computer competence.

\section{Computer use by K-12 Teachers}

There are a large number of studies of the various uses of computers in K-12 settings, many about the use of commercial software in the classroom. Gordon (2002) describes computer software which enables learning disabled students to read the same text as their classmates so that they can be more fully integrated into the regular education curriculum. In addition to allowing the students to understand the reading by offering definitions and reading the word aloud, it includes questions which help the students stay on task and remember what they have read. Some studies deal with the use of the Internet for research and for projects coordinated with other schools or government programs. In a follow-up of a project begun in 1988, McGrath and Thurston (2001-02) note the positive effects of long distance computer access in rural Kansas. When the original project was begun few computer training programs were available. The project supplied teachers with modems along with training so that they could communicate with their peers for teaching strategies and with graduate assistants for technical help. The follow-up research found that the teachers in the project were less anxious about computer use and were often technology leaders in their schools. The Ohana Foundation, a non-profit organization, commissioned a study of public schools, looking for leaders in technology use. Bossert (2001) describes the top schools and notes the use of networking in both rural and city sites. In Central Columbia, PA., a link has been formed among a consortium of schools as well as local colleges. This offers a 
lot of support and learning options for teachers. Wilson County, NC, a rural system, offered free home dial-up connections to all staff to allow access to the educational materials on the network. A major effort was also placed on staff development so that the teachers would feel comfortable using technology in their classrooms.

There are also studies which address the wide range of technologies used in K12 educational settings. Fleming-McCormick, (1995), studying K-12 teachers, noted that in the model technological schools they viewed, teachers used a minimum of a computer, video monitor, and VCR in each classroom. In four of the nine schools they studied, teachers used various technologies for classroom presentations. Students throughout the program had access to technology for instruction in content areas, computer skills and research. In a major study of teachers in K-12 across the country, the Office of Technology Assessment (1995) found more than half the respondents used VCR's TV's, and personal computers. These studies point out the range of technologies available to teachers, and attest to the fact that many teachers are already using earlier technologies, so the transition to computer use may then be easier for some. In fact, in a study of a new magnet school for math and science, Wright, Rice and Hildreth (2001) found that an increase of the use of new technologies (email, cd-rom) lessened the use of older forms (overheads, audio tapes). Access and support led to an increased use of more complex technologies.

Concerns about the integration of computers into classrooms were noted early on. In a review of research, Sudzina (1993) cited a number of studies covering the use of computers in $\mathrm{K}-12$ settings. One questioned teachers who had participated in the Apple Classrooms of Tomorrow and found that even with the technical and training support offered, many had difficulties incorporating computers into their classrooms. It was found that "Teachers must not only know how to use technology but they must also know how to teach differently and communicate new roles for themselves and their students" (p.7). Later, Chiero (1997) surveyed elementary school teachers and found that although computer literacy has increased - $74 \%$ rated their skills as moderate there were still $23 \%$ who rated themselves as barely computer literate. These concerns about integrating technology continue to be noticed. More recently, Wetzel (2001-02) found that middle school science teachers had concerns about their own readiness, beliefs and values, and they felt that support from the system was of great importance. The teachers also cited time, funding and access to hardware and software as additional problems. 
Computer use by Preservice Education Students

Studies of those training to become teachers parallel those of inservice professionals. They focus on the experiences of the preservice student teacher, touching on programs available and questions regarding adequacy of training. Marcinkiewicz and Wittman (1995) interviewed preservice teachers and followed them into their first teaching positions. During their own schooling, they were asked questions related to their expectations about whether or not they would use computers when they became teachers. After teaching for one year, they were asked to relate actual experiences. The authors found that the expectation of computer use exceeded the actual use, but use was greater than in an unrelated group of teachers. The authors noted that the higher expectations may be due to the training program in the university. Willis and Sujo de Montes (2002) studied the effects of separate technology course on the use of technology by preservice teachers. Although it was a small study, they did find that self-efficacy was increased, but integration of technology was not. It may have been due, in part, to a lack of technology use in the student teaching placements as well as the limited exposure to technology use in the classroom at the college level.

Wizer (1995) studied graduate education students who were enrolled in two distance education courses from across the country. They were asked about the benefits and limits of their online education. The results indicated that the newer students, those with less computer experience, found the bulletin board system was very helpful as a way to communicate with other students and with faculty. Abbot and Faris (2000) surveyed students' attitudes towards computers and found that the students experience using computers in their teaching, and the support they received from their faculty, increased their positive attitudes towards the use of computers in teaching. In an article by Robinson and Milligan (1997), a program was described which required education students to use a variety of technologies, including software packages, databases and spreadsheets. Each student had to create an electronic portfolio and web pages. They were also taught the management and evaluation of technology.

In a number of other studies, notice is taken of the need for this kind of preparation for preservice teachers. Handler and Strudler (1997) note that there are many articles pointing to lack of training and/or experience for preservice teachers regarding technology. Are the students "...asked to plan lessons that include 
technology components? Do they see technology modeled by the education faculty during their classes?" (p. 16). The authors also see problems with setting standards if staff/students have limited access to the technology they need. As Russett (1994) says, "...for education majors to be comfortable with computers/technology in the classroom, they need to talk about how to use the technologies along with the teaching methods" (p. 8). "...there is a need for an integration of the technology use with the methods/curriculum block for the students to see the potential for future use in the classroom" (p. 9). In her research review, Sudzina (1993) states that "Preservice teachers need to receive hands-on experience with computers and technology in professional educational environments..." (p. 8). As recently as 2000, Dawson and Norris found that research backed the need for authentic experiences for preservice students. The most important outcome they cite is increased confidence in the students' own skills.

\section{Computer use in Higher Education}

Along with studies of inservice and preservice teachers, researchers have looked into the ways in which college faculty use communication technologies. In a 1993 study of faculty in a science teacher preparation program, Pederson and O'Dell found that more than half were frequent users of overhead transparencies, video tapes, computers and slides. They also studied the differences between the amount of knowledge the faculty had about computers and what they wanted to know, as well as their use of a range of technologies. One finding was that only $12 \%$ stated that their doctoral programs had required computer classes, but $78 \%$ thought that this kind of training should have been included. Since that time, computer use has increased on all educational levels, with different approaches being used to increase technology use by education students. Ehman (2001) describes a pilot program which used stand-alone web modules in an attempt to integrate technology into a social studies methods class although the school still primarily uses a stand-alone course for technology preparation. Each module was based on national standards for the field and for technology skills. The author found that there was an increase in technology integration, and that students used the tools intelligently. There was a co-teacher, however, who was resistant to the use of technology, and remained so even at the end of the program. The author concluded "...that it is the teacher, not free-standing modules, that will make a difference 
in the extent to which methods class students integrate technology into their thinking and actions..." (p. 49).

Handler and Strudler (1997) stress the modeling of use by faculty and the promotion of the use of technology by students. They tried to help faculty find ways to integrate the standards of technology use developed by the International Society of Technology Education (ISTE). Kahn (1997) notes two reasons many colleges hesitated to incorporate technology into their courses. Some have developed separate courses for higher level students, and some worry about keeping up with the quickly changing technologies.

Along with the many studies documenting the ways in which communication technologies are being used in higher education, there are other studies documenting the obstacles to that integration. In her 1993 review, Sudzina found that "At the present time there appear to be few institutional incentives for teacher educators or preservice teachers to be "up to speed" with new technologies; those having individual expertise are often undervalued or worse, ignored." (p. 8). In 1995, Shenouda and Johnson discuss efforts to integrate computer technology into teacher education curricula. They found that although faculty used computers at home and special education faculty invited visitors to demonstrate uses of technology to the students, most other faculty considered themselves computer illiterate. Even in 1997, Kahn notes that "Within education facilities, professors modeling instructional strategies that make intelligent use of technology are...rare, and their access to technology to demonstrate such strategies is...constrained." (p. 25). As late as 1998, in a major nation-wide survey, Green and Eastman studied computer use in higher education. They found that just under one-half of United States colleges had strategic plans for information technology, up from $28 \%$ in 1990.

Purpose of the Study

Given the range of articles written, as well as popular news of changes in school programs, it is evident that use of communication technologies, specifically computers, is on the rise. Whether by choice or under pressure, educators are becoming more technologically literate. In many of the studies, this need for knowledge is of concern. Many educators are excited by the chance to use new tools, but lack the time, training 
and access necessary to become proficient. (Beichner, 1993; Office of Technology Assessment, 1995).

In terms of the K-12 teacher, the training and access is the responsibility of the school, district or the teacher on his/her own. For those who are training to become teachers, learning about new technologies and how to use them should be part of the higher education experience. Wiebe and Taylor (1997) note that "...many people obtain teaching credentials in the United States without any knowledge of computers because (1) their states have no technology requirements, and (2) their teacher education programs have no technology requirements." (p. 5). Some students will come to college already familiar with computers, having used them at home or at school. A large number of students, however, have had limited access. Even those who have used computers will not necessarily have experienced the many ways in which these tools can be used by teachers.

According the National Council for the Accreditation of Teacher Education programs (NCATE), as of 2000, accredited schools, colleges and departments of education should "...prepare candidates who can integrate technology into instruction to enhance student learning..." (National Council for the Accreditation of Teacher Education programs, p. 4). As of 2002, the majority of states (42) either require or reference national standards for technology competence for preservice and inservice teachers (International Society for Technology in Education, October 2002). These skills must be gained before new teachers are certified, and therefore students should have the opportunity to learn those skills before they graduate college.

Both faculty and administrators need to be aware of what technologies are currently being used in their colleges in order to determine where there might be a need for development and training. With the information gathered through this study, they can better decide on the emphases to be placed on training and equipment for teacher education purposes. Analysis of the patterns of computer use will put the data into perspective, and allow each college to assess the need for change in the ways in which computer technology is being used.

\section{Problem Statement}

In many of the studies cited above, a major concern is that the amount and depth of training of preservice education students in the use of computers is less than is felt to 
be necessary. This was evident in research about inservice, preservice and faculty members, and from the students' concerns about gaps in their own preparation. Over the past five years, standards for preservice students, student teachers, and first year students were developed by the International Society for Technology in Education (ISTE). Considering the findings of concern about preparation of education students, the development of national standards, and their adoption by NCATE, the problem statement of this research can be stated thusly:

To determine the correlation between the modeling of computer technology use by teacher education faculty and preservice student course requirements based on the International Society for Technology in Education standards.

In order to ascertain this information, data was gathered through a survey of faculty who reported their own modeling of computer use and their promotion of the use of computers by their students. Analysis was then made to determine if there were patterns in this use. Comparisons were also made to determine differences between Vermont colleges. In order to focus this research the following questions will be addressed:

- To what degree do faculty model the ISTE standards for preservice students?

- To what degree do faculty require that their students demonstrate proficiency in the ISTE standards for preservice students?

- What is the correlation between the modeling of computer technology and requirements faculty make of their students to the standards developed by the International Society for Technology in Education?

\section{Assumptions}

In order to complete any study, certain assumptions must be made. For this project, the following is expected:

- there is some use of computers on each campus

- there are differences in the use of computers among faculty 


\section{Limitations}

As with all studies, this one has its limitations. It is necessary to set parameters which allow the research to be comprehensive yet attainable.

- the area being studied was limited to Vermont

- the colleges included were only those which certify teachers for K-12 settings and offer specific education courses

- the faculty were limited to those who teach in programs leading to education certification

- technology studied was limited to computer use

\section{Summary}

In summary, there has been an increase in the use of communication technology in public school settings and in higher education. In many instances, hardware and software are purchased based upon public pressure or product availability. Although there may be information about what each school has, there may be little information about who is using the tools and in what ways they are being used. It has become crucial for those who will be teaching in $\mathrm{K}-12$ settings to be able to make educated decisions about the technologies they will use and to be able to assist their students with the technologies those students will have to use. How well these new teachers learn this depends upon how broadly they have been exposed to the appropriate communication technologies. In order to make informed decisions, both faculty and administrators should have current data on the use of these technologies, so that appropriate additional materials or training can be decided upon. The results of this research will supply Vermont educators with information about the use of computers reported by education faculty. Achleitner, Vowell and Wyatt (1995) state that "Educational change is proceeding at variable rates on university campuses, driven primarily by the speed of adoption of information technology, faculty willingness to experiment with technologies, and the positive stance of administrative leadership". (p.1) The analysis of the patterns of use in this research will not only clarify the existing situation, but prove useful in future planning. Since the ISTE standards have been adopted by the National Council for Accreditation of Teacher Education programs, 
colleges will find it useful to know how closely their faculty come to integrating these standards into their curricula. 


\section{Chapter Two}

Review of Literature

As presented in Chapter One, computers are quickly becoming a part of our school systems, from kindergarten to college. There is a demand from the public that students not be underprepared for their futures. There is a growing awareness among educators that technology skills will be necessary in all of what students do, in whichever occupations they choose, and in their lives outside of work. Although education needs to be more than just skill training and job preparation, some level of competence in computer literacy will be necessary. In this chapter, the literature will be reviewed for the views of professionals on the use of computers by $\mathrm{K}-12$ teachers, preservice education students, and higher education faculty, as well as research into computer competence standards.

\section{Computer use by K-12 Teachers}

Public schools are rising to the challenge, trying in many ways to add technology to their existing curricula. Programs start as early as kindergarten, as Alfaro (1999) shows. A school system, becoming frustrated by low reading scores in poorer schools, paired teachers in four schools with a shared technology-based reading program, and proceeded to increase the reading readiness of ninety percent of the students. Berg, Benz, Lasley and Raisch (1998), studying what had been chosen as exemplary elementary programs, found teachers using technology to motivate students, be more creative about designing assignments, and to change their classrooms to a more student-centered approach. Although there are many articles describing successful programs, a number of problems seem to have arisen. Eastwood, Harmony and Chamberlain (1998), and Poole and Moran (1998) found that although hardware and software was available, teacher training was lacking. In the former instance, teachers volunteered to participate, and wound up using only those technologies with which they were familiar. In the latter article the authors note that one-shot workshops, lack of continued support and isolated knowledge have caused difficulties in programs that could have been promising. They suggest a teacher teaching teachers model in order to provide ongoing support and meet the needs of teachers hoping to integrate technology into their classrooms 
As computers become more prevalent, teachers find themselves having to learn skills on their own. Although there are workshops available, follow-up has not been typical. In an attempt to alleviate this problem, some schools have used telecommunication technology. Weisenhoff and Johnson (1998) write about a program which developed a web page teachers could access. They were able to post information about other web pages which would be useful for all the teachers. Even those teachers who are not finding the integration of technology to be their most pressing problem can be helped by telecommunication technology. For new teachers, Eisenman and Thornton(1999) describe a telementoring program which helped teachers through their first year, using email and a listserv.

In specific studies performed to assess existing or new programs, some patterns become discernible. With technology support and specific goals in mind, teachers report enthusiasm about learning and using new technologies. Pan and Lee (1997) studied students in a graduate education class. Those who were already teaching were more motivated and focused, in large part because they knew why they were learning and what they would do with the skills they were gaining. After setting up a new program which gave teachers computers in their classrooms, one week of training, workshops in the school, and a technology support person in each site, Keeler (1996) found that teachers, students and administrators all felt positively about their experiences. In cases without adequate training or resources (Hecht, Roberts \& Schoon, 1996; Rice, 1995), teachers expressed feelings of isolation, being overwhelmed, needing a resource person, and having difficulties developing the appropriately integrated classrooms. Chiero (1997) surveyed teachers about the frequency of computer use and found onsite support generally not available.

Researchers talk of changes in the classroom from traditional passive situations to those in which the student takes an active part in his/her education (Kukes, Dodaj, \& Macdonald, 1999). There is an expressed request for teachers to use technology in their classrooms and for administrations to be active in their support of these changes (Marsh, 1999). Yildirim, Ozden, and Aksu (2001), in a study of high school biology students, found that there is greater retention of information when using hypermedia than when using traditional/lecture methods. 
Computer use by Preservice Students

Studies show a variety of methods to teach computer skills being used successfully, many relying on integration of technology into the curriculum and more real-life, hands-on experiences. Halpin (1999) studied seventy-three preservice students before and after a methods course, half of whom learned in an environment in which technology was integrated and computer use was required. Those students reported more confidence in their computer skills and used their skills more frequently in their classrooms during their first year of teaching. In Ropp's study (1999), 53 teacher candidates were more positive in their attitudes towards computers even with a limited amount of hands-on experience in the classroom. The lowa teachers studied by Topp (1996) were pleased by the integrated technology course they had taken, but still felt under prepared. They suggested that modeling by faculty members would have been helpful. One purpose of a course in technology for productivity at Leslie College (Robinson \& Milligan, 1997) was to model teaching with technology, since few other integrated courses were available. In an exploratory course in geometry at the University of Georgia, researchers Oppong et al. (1997) found that their objective of modeling instructional use of technology helped the students feel more relaxed with the technology by the second week of the course. By using telementors, Thurston, Secaras and Levin (1997) modeled the use of telecommunication technology and found that technology had become an integral part of the students' lives.

Studying undergraduates, Zhang and Espinoza (1998) found that those who saw specific benefits to the knowledge wanted to learn more and were less anxious about computers. The results suggest that less threatening experiences and more practical uses would be preferable. In a report on a project to set up technology rich field experiences, Dawson and Norris (2000) noted students reported more skills, more knowledge and had a more positive attitude toward the use of technology in the classroom. Stephens (2000) analyzed the use of technology in field-based experiences of 263 students. The study found that when students observed technology being used in their field placements they were more likely to use it themselves. Also, a strong correlation was found between preservice student use of technology and modeling of the use of technology by their faculty.

Not all studies of technology use by preservice teachers reported positive outcomes. Wetzel, Zambo, Buss and Arbaugh (1996) describe a project to mentor 
student teachers in which problems with lack of up-to-date technology in the classroom, lack of technology training of the mentor, and few opportunities for the students to integrate technology into their lessons. In the first year of a program designed to allow students to observe technology-using teachers, Vannetta (2000) noted that the teachers who were to integrate technology into their courses had not had the time to fully develop their programs. A study by Vagle (1995) looked at methods courses in different institutions and documented the ways in which technology was used and required. The author notes that just having an introductory course doesn't necessarily lead to integration of that skill into teaching and recommends including technology into methods courses. It was found that "...the hardware technologies required of the pre-service teachers follow closely the patterns of hardware technologies used by the instructors." (p.240). This was also true of software. When asked why the use of technology was limited, three responses were given - a course was given, but later in the curriculum; it was hard for faculty to keep up with both course content and technology; access to both hardware and software was limited. Regardless of the problems cited, the majority of studies agree that there is a need for an increase in the integration of computer technology into preservice teacher education programs.

\section{Computer use in Higher Education}

As was noted earlier in this paper, use of computer technology in $\mathrm{K}-12$ settings is increasing. Studies show that computer technology use in higher education is also growing. The Campus Computing 2000 Project (Green \& Eastman, 2000) found that $59 \%$ of college courses use email, up from $44 \%$ in 1998 . Aside from its usefulness throughout the institution, schools of education need to increase their use of technology in order to prepare their students for the responsibilities those students will face on the job.

At Towson University, Wall, Helfrich and Jones (1995) report of a project in which they were instrumental in adding to the technology used by education faculty members. Each faculty member was given a personal computer, and later the campus was networked. After a few years of slow growth, the faculty was surveyed and 'academies' were set up to improve their skills in specific areas. Opportunities were also set up for the faculty to work in local schools, gaining real-life experiences in the use of computer technologies. "...when given the opportunity, faculty are willing to improve their 
knowledge of technology and to integrate that knowledge into their classes" (p. 8). O'Bannon, Matthew, and Thomas (1998) found that a program which has adequate resources and administrative support can alleviate faculty reticence, which was due to additional time commitments and resistance to appearing incompetent.

In a program designed to increase the use of technology in higher education, Young (1999) found that hiring graduate students in the professor's field, rather than computer science students, improved the likelihood of success for the educators. There was a greater ability to communicate about both the technology and the content. Malinconico (1999) described a program to increase the technical knowledge of faculty by offering a variety of training venues, rather than the usual one workshop or one week of training. Educators have known for years that different people will learn better under different conditions.

Some researcher (Dusick, 1998) found that even with increased access to computers, there has not been a comparable increase in usage. "Research indicates that teachers are less likely than other professions to use computer technology" (p. 125). In Mitra's (1998) pre and post assessment survey of the use of computers by faculty in a newly upgraded system, it was found that increases were made in electronic mail, but not in more complex applications (such as multimedia). In a 1999 study, Mitra, Steffensmeier, Lenzmeier, and Massoni found that in order to facilitate an increase in faculty computer use, adequate training and infrastructure support were needed. Studying faculty development, O'Bannon (1997) found limited access to technology, lack of administrative support and lack of risk-taking faculty led to faculty resistance to computer technology. Vannetta and Beyerbach (2000) stressed a need for training when looking into the integration of technology for faculty and preservice teachers.

The research gathered has shown a recognition of a need for technological competence on both the $\mathrm{K}-12$ and university levels. This is being achieved in different ways and with different levels of success. There are some instances of cooperative programs between the two groups, but usually this revolves around a teacher education program. Pugalee and Robinson (1998) noted that inservice teachers rely on recent graduates to assist in the application of computer technology, but the graduates also felt unprepared. Through an attempt to increase technology infusion in their college, Thomas and Cooper (2000) found that increased integration led to more increased integration by preservice teachers. That is, with each new instance of technology use, the faculty discovered new ideas and were then able to increase the integration of 
technology. With motivation and interested faculty, integration of technology can proliferate.

\section{Computer Competence Standards}

In all of these studies, the preparation of educators to use technology is viewed as important. If this need is there, it is also important to decide what constitutes adequate preparation.

In 1995, Higdon traced the evolution of definitions of computer literacy, through literature and course offerings. He found that as computers became part of educational systems, the initial goal was to know the computer, then to know some specific applications. Later definitions included integrating this knowledge, developing one's own presentations, and using telecommunications. As users learned more about the computer's capacity, the definition of literacy was expanded. In an attempt to assess the acceptance of definitions of competence, Hirumi and Grau (1996) did a content analysis of sixty competencies and found that only two were specified by a majority of state standards, texts and journal articles combined. There appears to be a problem of consensus. The article also suggests "...computer use should be infused throughout preservice teacher preparation programs. For educators, computer literacy is becoming essential for school productivity. However, most preservice programs offer only one computer course as an elective. ...it is evident that a single course cannot provide necessary instruction. In addition, technology may never be effectively integrated with public education unless teacher educators sufficiently model its use in universities...Teacher educators must come together to ensure that teacher candidates are presented with a wide range of experiences throughout their preservice training." ( $p$. 14).

The International Society for Technology in Education (ISTE), through its National Educational Technology Standards for Teachers (NETS) Project, funded by the Preparing Tomorrow's Teachers to Use Technology federal grant program, has developed a series of standards for technology use by educators (International Society for Technology in Education,2000). In 1990, ISTE affiliated with the National Council for the Accreditation of Teacher Education (NCATE), the only agency recognized by the U.S. Department of Education for this task (Wiebe, Taylor \& Thomas, 2000). As early as 1993, ISTE had developed a draft of technology standards for teachers. In 2000, the 
third edition was presented and these guidelines have been adopted by NCATE. These standards (ISTE, 2000) have been used as a model or guideline for a number of studies describing the process of assessing students to determine if they meet particular standards. NETS for teachers is composed of four sets of profiles: general preparation, professional preparation, student teaching/internship, and first-year teaching. Each builds upon the learning covered by the prior profiles and includes information gained from college courses, field work, and teaching experiences.

In the state of North Carolina, for example, there are requirements for both initial licensing and for inservice teachers. Algozzine et al. (1999) describe a matrix developed for faculty and students at the University of North Carolina, based on that state's technology competency standards. The authors also note that the standards in the state closely match those developed by ISTE. Also in North Carolina, Levin (1996) describes how the portfolio is carried through four semesters, and has developed a rubric students can follow to assess their own progress. Petrakis, (1996) describes how the University of Nebraska developed a tool and now assess the competence in educational computing of students, using a portfolio. Because students have to show basic competence at the beginning of the program, faculty can go beyond that level in their coursework. At Chestnut Hill College, a long term goal is to fuse the applied technology and education programs. In order to do this, they used NCATE standards in developing courses for its education program (Kahn, 1997). It was felt that the use of nationally known standards assisted in the success of the program.

From a survey done by the Milken Exchange, Dewert (1999) was able to determine that eighteen states require preservice teachers to meet technology-related requirements for licensing. At the same time only four required this of practicing teachers, and only three of new administrators. The states answering yes may set up requirements in many ways - completion of a course, use of a portfolio, or a formal assessment.

Levin, Buell, and Levin (2000) describe a database developed for education faculty and students so they can correlate their skills with the ISTE standards. As of 2000, their state, Illinois, along with Ohio, Wisconsin, North Dakota, Washington, Hawaii and Georgia, had begun to use the ISTE standards (Wiebe et al. 2000). In Michigan, Hope College faculty, as reported by Cherup and Linklater (2000), coordinate ISTE skills throughout the program to make sure progress ensures. 
Clearly, if computer technology is going to be expected to be used in $\mathrm{K}-12$ educational sites, preparation of new teachers, as well as those of practicing teachers and their administrators will have to expand. As of 2001, NCATE required technology competence, based on acceptance of ISTE standards. Therefore, it behooves colleges to know what the correlation is between the use of computer technology by preservice teachers and their exposure to technology in college. How are they learning what they should know, according to nationally derived standards? Are they learning, through observation or assignment, what they will need to know when they teach in $\mathrm{K}-12$ settings? This research addressed one portion of the question by determining how faculty report their performance and requirements in relation to ISTE standards for preservice students. 


\section{Chapter Three}

Research Methods

The use of computers in educational settings is increasing, due to pressure from researchers, educators, business owners, and parents. Documentation of this addition to the tools available to educators includes specific uses of computers by higher education faculty, preservice students and K-12 teachers. Research details the spread of the technology, as well as describing specific uses in all grade levels.

In addition, researchers have found difficulties with the integration of technology in both higher education and $\mathrm{K}-12$ settings. Faculty have noted a need for technical and administrative support, additional access to computers and peripheral hardware, and information about what was available in their fields (Cherup \& Linklater, 2000, Mitra et al. 1999). The problems researchers have found among school teachers include lack of adequate training and lack of time to work on new skills (Eastwood et al, 1998, Poole \& Moran,1998). Researchers suggested a few ways to improve preservice students' training, including modeling the use of computers in the classroom, and hands-on experiences in their field work (Halpin, 1999, Ropp, 1999). All three research areas, higher education, preservice, and inservice, note the need for additional training. Among preservice students there were numerous findings that modeling of computer use by faculty was beneficial (Oppong et al. 1997; Robinson \& Milligan, 1997; Stevens, 2000; Thurston et al. 1997).

Along with findings about needs in the educational community for additional support and training was a need for definitions of computer literacy and computer competence. The International Society for Technology in Education (ISTE), in collaboration with the National Council for Accreditation of Teacher Education (NCATE) has developed a series of standards for K-12 students, education students and K-12 teachers.

This research attempted to determine the degree to which faculty are modeling computer technology use and the degree to which they require those skills of their students in order to discover if faculty are using computers in ways which will enable preservice students to meet ISTE standards. The research was conducted by identifying 
the problem, interpreting the results of the analysis, and developing conclusions and recommendations.

In order to conduct this research the following methods were employed: 1) identify the problem statement and the research questions, 2) review the literature, 3) identify and describe the population to be studied, 4) describe the instrument to be used to collect the data, 5) analyze the data, and 6) summarize the analyses and make conclusions and recommendations.

\section{Problem Statement and Research Questions}

While doing research in vocational rehabilitation I became aware of the changes in that field due to computerization of various processes. There were also problems noted with the integration of computers due to training and access issues. My background in education led to questions about the process of computerization within the K-12 setting. While working in two elementary schools I found evidence of the spread of hardware but not the integration of the use of computers into the curriculum. Observations of classes in a school of education also proved that although computers were available, the use of this technology was limited. Since these students will be going into the $\mathrm{K}-12$ classes, and there is pressure for educators to use computers with their students, the experiences of the students in the college should lead them to greater rather than lesser use of computers. In order for students to learn about the new technologies their faculty must include its use in their curricula.

This research is concerned about the use of computers by higher education faculty as it relates to their students. The problem of this study is:

To determine the correlation between the modeling of computer technology use by teacher education faculty and preservice student course requirements based on the International Society for Technology in Education standards.

In order to determine what relationships exist, this research focused on the following questions:

- To what degree do faculty model the ISTE standards for preservice students?

- To what degree do faculty require their students demonstrate proficiency in the ISTE standards for preservice students? 
- What is the correlation between the modeling of computer technology and the requirements faculty make of their students, based on the standards developed by the International Society for Technology in Education?

Review of the Literature

Once a problem statement was identified, existing research was examined to determine what was already known and where there were gaps in the record. Included in this search were studies on computers used by students and teachers in K-12 settings, and by students and faculty in higher education programs. Journals and texts available through West Virginia University and online were augmented by those from the University of Vermont. Research contained studies done locally, statewide and nationally, by private and public agencies. Topics ranged from descriptions of the integration of technology into individual classrooms to the issues of what technology skills should be included into higher education programs.

\section{Description of Population to be Studied}

Most national studies of technology use in higher education gathered data from surveys given to or conversations held with technology executives. Statewide coordinators or administrators in educational institutions answered questions about technology use in their systems. Based on these findings from the literature review it was determined that there was a need for information gathered directly from faculty members. An overview of state-level use of technology (Meyer, 01), found that 26 states had technology requirements for teachers applying for licensure, but as of that time, Vermont did not have specific requirements.

As with all states, Vermont has a process for teacher licensure, but details about technology skills had been left to the colleges (Wolk, 1998). According to the state requirements as of 1998, prospective teachers needed to have the "ability to select and use appropriate technology within the endorsement area" (section 5235.8, p. 7), and to "....integrate current technologies in instruction, assessment and professional productivity" (section 5235.19, p. 8). There was no listed assessment or course requirement for either statement. Therefore, the individual educational institutions must 
develop programs or determine curricula which would assist their students in meeting the state requirements.

When doing survey research, a variety of sampling procedures can be used. "In purposeful sampling, researchers intentionally select individuals and sites to learn or understand the central phenomenon\{" (p. 194). Within this type of sampling is homogeneous sampling, in which "...the researcher purposefully samples individuals or sites based on membership in a subgroup that has defining characteristics" (p. 196) (Creswell, 2002). Since the goal of the study was to determine the correlation between teaching and standards for students in teacher preparation programs, the population eligible was that in institutions which offer certification in education and are those whose responsibilities include direct teaching of students in teacher preparation programs (see Table 1).

\section{Table 1}

Colleges/Faculty Eligible for Participation in the Study

\begin{tabular}{lll}
\hline College & Status & Number of education faculty \\
\hline Castleton & State & 8 \\
Champlain & Private & 3 \\
College of St. Joseph & Private & 3 \\
Green Mountain & Private & 2 \\
Johnson & State & 5 \\
Lyndon & State & 5 \\
Middlebury & Private & 3 \\
St. Michaels & Private & 8 \\
University of Vermont & State & 32 \\
\hline Total Eligible & & 69 \\
\hline
\end{tabular}

Numbers based on 2000-2001 college catalogues and Vermont Department of Education web site.

A list of such institutions was obtained from the Vermont State Department of Education. Catalogues for each college were then used to ascertain if the programs 
were comparable to one another; that is, did each college have an undergraduate program with faculty and students involved in direct teacher preparation coursework. They were also used get the names of specific faculty who were directly involved in the education of students in the teacher preparation programs. Each college's web site was also used as a reference, if that information was available online.

Initial counts predicted a population of about 100, but additional information from the colleges indicated that some of the faculty listed were not currently teaching (on sabbatical, researchers). After they were removed from the eligible population, the total number of appropriate faculty dropped to 69 members in nine colleges. This list includes the state university - the largest preparer - whose faculty approximately equals the number of those at all the other schools. Faculty numbers in those small schools range from three to eight, and in the University of Vermont there are thirty-two. Subjects were full-time faculty at colleges in Vermont which certify students to be teachers in PK-12 settings.

\section{Description of Instrument to be Used}

Since the goal of this study was to assess correlation of teacher modeling and student course requirements with specific standards, an instrument was developed (see Appendix A) which is based directly on those standards. According to the National Educational Technology Standards for Teachers Project (International Society for Technology in Education, 2000), there are specific profiles for each stage within teacher preparation programs, from general preparation through the completion of the first year of teaching. The profiles build on previous standards to reflect what preservice students learn as they progress through their teacher education programs. Since this study looked at the correlation of faculty actions to student standards, the items chosen are the two lists which pertain to those skills gained prior to the culminating student teaching or internship experience (ISTE, NETS Standards, p.16). These are the general preparation performance profile (questions 1-17) and the professional preparation performance profile (questions 18-41). The general preparation standards are expected to be met early in the student's preparation to teach, while the professional preparation standards should be met before the student participates in the final student teaching experience. 
The instrument consists of two sections. Section one presents a list of forty-one standards about which each respondent answered two questions. The first question was "To what degree do you model the following standards to your students" and the second question was "To what degree do you require your students to show proficiency in the following standards". For each standard the respondent replied using a Likert-type scale. The second section consisted of a set of demographic questions regarding teaching experience and responsibilities. It also included a question about obstacles to and/or support for the inclusion of these standards, and space was allotted at the end for respondents to expand on their comments. Additional data was gathered from each survey regarding the type (private/public), and size of the institution.

\section{Method of Data Collection}

As per research protocol, a human subjects exemption application was completed before any subjects were contacted. A pilot group was identified and given the survey, cover letter and explanation page, and asked to review all the items. This group was made up of faculty who were currently teaching but did not work with pre-service students. Since the standards were taken directly from the ISTE standards and would not be able to be altered without altering the basic question of the research, their content was not an issue. What was of concern was the readability of the material, the effectiveness of the format, and any mistakes which needed to be corrected. Pilot members recommended shortening the cover letter, clarifying two definitions and two background questions The suggestions regarding the format included the placement of the tracking number, the color of the paper (the survey different from the other papers), and the addition of directions at the top of each page of the questionnaire.

Once the pilot group had completed their task and suggested changes were addressed, the survey, with a cover letter (see Appendix B) explaining the instrument and its purpose and an instruction sheet for details about completing the questionnaire (Appendix C), were mailed to each targeted faculty member. The mailing included a pre-addressed stamped envelope in which to mail the survey back. Instructions stated that the survey should be returned within two weeks. Each survey had a code number which matched the name of the faculty member to whom it was mailed. This was needed so that those not responding could be recontacted, but respondents were assured that the information gathered would be confidential. Those who did not return a 
survey after two weeks got a follow-up reminder through their college email address. Those who did not respond to that reminder were sent a second copy of the survey and cover letter. After this, no further attempts were made to retrieve surveys, and all the data received was then entered and analyzed.

\section{Statistical Analysis}

This study was based on a survey consisting of a questionnaire that contains two Likert-type scales. Tuckman (1988) states that "A Likert scale is a five-point scale in which the interval between each point on the scale is assumed to be equal." Some research notes debates about the number of choices which should be available to the respondent (Black, 1999). Others (Munshi, 1990), suggest seven to nine rather than five choices are optimal. Pannell and Pannell (2000), note that "Two to four categories are not enough: responses to the four point scale (e.g. Strongly agree, agree disagree, strongly disagree) have been found to not collapse down into a two point scale; almost one in five respondents who answered on the positive side of the four point scale answered on the negative side of the two point scale." Based on these and other studies, this survey held to the traditional and most widely used choice of five points. For this instrument, the scale registered the degree to which the respondent's actions correlated with each existing standard.

Although there may be some question about the robustness of a self-report survey, self-administered questionnaires have some advantages. According to Bernard (2000), there is more consistency in the way in which respondents receive questions, the questions can be more complex and lengthy, and can be confidential, unlike personal interviews.

Many survey instruments are assessed for content validity. According to Kerlinger (1986), "Content validity is the representativeness or sampling adequacy of the content ... of a measuring instrument". Cronbach's alpha is also used to determine how well items on a scale are correlated. Since the items on this scale are quoted directly from the standards, and it is the adherence to not the acceptance of these standards that is being questioned, neither of these types of assessments is warranted.

In determining which assessments were to be used, consideration was given to whether or not the data could be accepted as continuous or ordinal. According to Black (1999), when discussing the quantifying of survey data using Likert-type scales, since choices will be translated into numbers and those will relate from person to person in the 
same way, then results can be dealt with as interval. For the purposes of this study, the data was calculated as continuous, except for three demographic questions which resulted in ordinal data.

Once all the data were gathered, recorded and verified through second party proofreading, analysis was completed using JMPin statistical software (Sall, Lehman, \& Creighton, 2001). For each of the forty-one standards studied, two questions were asked. For question one: "To what degree does the faculty member model the standard for the student", means and frequencies of the responses were computed to analyze modeling behavior of the faculty member for each standard. For question two: "To what degree does the faculty member require the student to exhibit proficiency on the standards", means and frequencies of the responses were computed to analyze requirements expected of the students for each standard. To answer research question three, what is the correlation between the responses to survey questions one and two, the mean score for faculty modeling of each standard was compared with the mean score of the degree to which they require that standard of their students. In addition, the difference between each faculty member's reported modeling behavior and their expectations of students was analyzed using t-tests to determine if the differences between these means was significant. Pearson product-moment correlations were then calculated to determine if there was a significant correlation between the standards, and then between the standards and specific demographic data.

All of the standards in the NETS (National Educational Technology Standards) project are grouped into six categories, based on their applications. These are 1) technology operations and concepts; 2) planning and designing learning environments and experiences; 3) teaching, learning and the curriculum; 4) assessment and evaluation; 5) productivity and professional practice; and 6) social, ethical, legal and human issues. Means of these categories were examined to determine if there were any significant relationship between these categories and the standards which would not have been evident in individual correlations. These categories also allow users of the research to better understand the areas which may need attention by grouping apparently disparate standards.

Demographic data were collected and summarized using descriptive statistics and frequency distributions. Initially, means were examined to explore the range of those responses. Pearson product-moment correlations were then used to assess the correlation between individual responses and personal characteristics. Additionally, 
contingency tables were run on institutional information to assess the correlations with the size and type of institution and with the use or requirement of use of technology. Comments about obstacles to technology use and additional comments, if present, were organized to serve as additional information on areas of concern or satisfaction with the process of integration of technology. Although open-ended questions are divergent that is they are open to unpredictable responses - this allowed faculty to write about the situations which might be particular to their institutions.

\section{Summarize Findings, Draw Implications and Make Recommendations Based on the} Analysis.

Once the data were analyzed, summaries were developed examining the relationships between the variables. Since NCATE requires these standards to be met (National Council for the Accreditation of Teacher Education Programs, 2000), and many states are incorporating technology competency into their own standards, institutions will need to show that their students will have access to the training they will need. In Vermont, the ISTE standards have just been included (as of 2003) in its requirements for new and relicensing teachers (Vermont State Department of Education, n.d.). The conclusions drawn from this study assessed how closely faculty reported their modeling and requirements for their students came to the existing standards, and how other factors, both personal and institutional, correlated to the reported actions.

Recommendations include broadening the population to include additional states in order to make the data more widely applicable, as well as including students to assess their views about faculty modeling and requirements of the ISTE standards. 


\section{Chapter Four \\ Research Findings}

Throughout the first two chapters it was demonstrated that computers had become a part of the educational process. It was also noted that the national agency which accredits higher education programs (NCATE) was adopting a set of standards developed by ISTE for students who were in teacher preparation programs. If there are standards which students need to meet, then it is necessary that they be given the opportunity to gain the skills. It was posited that faculty should be modeling or requiring at least some of these standards to some degree. The research questions which were generated are stated below.

1. to what degree do faculty model the ISTE standards for preservice students?

2. to what degree do faculty require their students to demonstrate proficiency in the ISTE standards for preservice students?

3. what is the correlation between the modeling of computer technology and the requirements faculty make of their students, based on the standards developed by the International Society for Technology in Education?

In Chapter 3 a method was described which gathered information about faculty teaching methods and how they relate to those standards. A questionnaire was developed and mailed. After the initial mailing, a total of 23 questionnaires were returned. Of those, six respondents returned surveys or letters stating that they would not be returning a completed survey. The email reminders brought in 25 responses, with thirteen stating they would not complete the survey, and 12 stating that they would return the survey later. Five of those surveys were received. The second paper mailing brought in six more completed surveys along with five more who would not complete the survey. Within the next month, four more questionnaires were returned, bringing the total to 32. The surveys had been sent to nine institutions: three state schools with 18 faculty, four private schools with 19 faculty and one state university with 32 faculty. Out of a population of 69 eligible faculty, $32(46 \%)$ returned questionnaires. This chapter will describe the results from the analysis of the data returned.

Respondents were presented with a questionnaire in two parts. Subjects were asked to circle choices on a Likert-type scale related to their methods of teaching with 
and about technology, to answer some specific questions about their teaching history, and express their opinions about support or obstacles regarding technology integration. This research produced three kinds of data. First, there were the multiple choice responses regarding the degree to which respondents modeled or required the standards. Next there were short answer questions designed to elicit information which might categorize faculty in order to ascertain if relationships existed between these variables and the responses in the first section. Finally, respondents were given a chance to express their opinions about the support for or obstacles to integration of technology into their curricula in open-ended questions. Analyses were done for each type of data using both qualitative and quantitative statistics.

For each standard, respondents were asked to indicate to what degree they modeled or required their students to show competence in that standard. Respondents were given the direction to rate as a one those standards they modeled or required in fewer than one-tenth of the classes/semester or as a minor component of the course, as a five those they modeled or required in more than two-thirds of the classes/semester or as a major component of the course, and to choose two, three or four to indicate that their methods reflected a degree between those choices. Although the format resembles a Likert-type scale, the choices differ from the traditional agree-disagree wording. Instead of 3 meaning an in-between non-committal answer, the scale is really a continuum, with any answer meaning the standard was at least touched upon, and those choices around three indicate that faculty see their methods as incorporating that standard a moderate amount of time.

\section{Survey Part I}

Question One: To what degree do faculty model the ISTE standards for preservice students?

The means generated for each standard modeled ranged from 2.0 to 4.0 . It was found that $37 \%$ of choices were 3 or more - an indication that over one-third of the respondents reported modeling and requiring the standards at a moderate to high degree. No respondent stated that he or she found any specific standards not applicable to his or her courses, although some choices $(8 \%)$ were left blank.

In order to facilitate the descriptive interpretation of all the forty-one means of the standards required of students, the decision was made to condense the means into 
three categories: less than 2.7, between 2.7 and 3.3, and more than 3.3. The responses were also separated into general (standards 1-17) and professional (standards 18-41). General standards are those presumed to be achieved early in the students' educational career, while professional standards should be mastered before student teaching begins.

\section{Table 2}

Distribution of means for standards modeled by faculty

\begin{tabular}{llll}
\hline Means & Totals & General & Professional \\
\hline less than 2.7 & $42 \%$ & $47 \%$ & $39 \%$ \\
2.7 to 3.3 & $43 \%$ & $18 \%$ & $58 \%$ \\
more than 3.3 & $17 \%$ & $35 \%$ & $4 \%$ \\
\hline
\end{tabular}

Note. Totals may not add to $100 \%$ due to rounding.

Question Two: To what degree do faculty require the ISTE standards for preservice students?

The means generated for each standard required also ranged from 2.0 to 4.0. It was found that $34 \%$ of these choices were 3 or more - an indication that just over one-third of the respondents reported requiring the standards at a moderate to high degree. Again, no respondent stated that he or she found any specific standards not applicable to his or her courses, although some choices were left blank.

\section{Table 3}

Distribution of means for standards required by faculty

\begin{tabular}{llll}
\hline Means & Totals & General & Professional \\
\hline less than 2.7 & $51 \%$ & $53 \%$ & $50 \%$ \\
2.7 to 3.3 & $39 \%$ & $24 \%$ & $50 \%$ \\
more than 3.3 & $10 \%$ & $24 \%$ & $0 \%$ \\
\hline
\end{tabular}

Note. Totals may not add to $100 \%$ due to rounding. 
In order to facilitate the descriptive interpretation of all the forty-one means of the standards required of students, the decision was again made to condense those means into three categories: less than 2.7, between 2.7 and 3.3, and more than 3.3. The responses were also separated into general (standards 1-17) and professional (standards 18-41), those sections relating to the approximate time in the education program when these skills should be covered.

Question Three: What is the correlation between the modeling of computer technology and the requirements faculty make of their students based on the standards developed by the International Society for Technology in Education?

Using descriptive methods, the means for the degree each standard was modeled were compared with the means for the degree each standard was required. It was found that out of 41 means, 21 (50\%) were rated as being a higher degree for modeling than for required, 18 were rated lower and two were equal. When these were separated into general and professional categories, it was found that faculty were more likely to model than require general standards (those related to skills gained early in the program) and more likely to require than model professional standards (those related to skills gained right before student teaching).

As in the earlier analysis of modeling and requiring, the means were split into three groups, low (less than 2.7), moderate (2.7-3.3) and high (more than 3.3). In summary, Table 4 shows that the results suggest the reported degree of modeling and the reported degree of requiring show only slight differences.

\section{Table 4}

Number of standards modeled and required, by means

\begin{tabular}{lcc}
\hline Means & Modeled & Required \\
\hline Less than 2.7 & 17 & 14 \\
2.7-3.3 & 18 & 23 \\
More than 3.3 & 6 & 4 \\
\hline
\end{tabular}

In order to determine if there was any statistical significance to the observed differences between modeled and required standards, t-test were computed for each 
standard. It was discovered that although there were observed differences, only two standards showed statistically significant differences (see Table 5). This assessment mirrored the observations that showed a relatively even spread among the choices the faculty reported (see Appendix D).

\section{Table 5}

Standards exhibiting differences between degree modeled and degree required

\begin{tabular}{lllll}
\hline Standard & required mean & modeled mean & t-ratio & p value \\
15 & 3.25 & 3.83333 & -3.24919 & $0.0029^{*}$ \\
35 & 2.75926 & 3.2963 & -2.38938 & $0.0244^{*}$ \\
\hline
\end{tabular}

Note. Standard 15 - exhibit positive attitudes toward technology uses that support lifelong learning, collaboration, personal pursuits, and productivity; Standard 35 - participate in online professional collaborations with peers and experts. ${ }^{*} \mathrm{p}<.05$.

After initial examination of the means and the t-test, a Pearson product-moment correlation was calculated, with an alpha of 0.05 , on the modeled and required scores for each standard. All calculated $r$ values exceeded the critical values (at $p<.05$ ), based on the degrees of freedom for each standard (see Appendix ?). Examination of the results showed a strong positive correlation, since $68 \%(28)$ of the reported responses were .81 or higher.

All the assessments up to this point had been based on comparing results of analysis on individual standards. These standards, as developed by ISTE, fit within six broad categories which are intended to be used as a framework for educators to use when planning technology-rich environments. They cover general technology skills and knowledge, use of technology in educational settings and professional practices, and ramifications of technology applications. Each of the specific standards developed by ISTE for preservice students were taken from two scales. Standards 1-17 represent the general profile grouped which includes those areas which should be covered in the beginning of preservice students' education classes. Standards 17-41 represent the professional profile and include those skills and experiences which should be completed before they begin student teaching. The standards, as numbered in the questionnaire, were grouped by ISTE into their broad categories in the following way: 
Table 6

ISTE Categories for National Educational Technology Standards

Standards

Category

General

Professional

I. Technology operations and concepts

$1-9,11-13,16$

$18,20,21,30$

II. Planning and designing learning environments and experiences

$-\cdot-\cdot-\cdot--$

$19-22,24-27$

III. Teaching learning and the curriculum

$3-5,8-10,12$

$18,19,23-26,34,35$

IV. Assessment and evaluation

$3,7,8,12$

23,24,27-32

V. Productivity and professional practice

$3-13,15$

$19,27,32-36$

VI. Social, ethical, legal and human issues

$19,24,27,37-41$

Means for each standard within the categories were grouped by low (less than 2.7), medium (2.7-3.3) and high (more than 3.3). The intent was to see if there were any apparent differences when data was reqrouped. That is, were there any patterns corresponding to the groupings which ISTE had developed. Within the general grouping, means were spread from 2.79 to 3.35 , whereas in the professional grouping all means were below 3 and ranged from 2.44 to 2.92 .

Using the compiled means, two tables were created showing what percent of the means in each category fell into each of the groupings (low, medium and high), first by those modeled, then by those required.

From Table 7 we can see that when grouped into categories, the means of the individual standards included in II and VI were not over 3.3, and in categories IV and VI the majority of the means model to a low degree. It should be noted that no general performance standards were placed by ISTE into category II, therefore that column is based only on professional performance standards. We can also note that in categories I, III, and V more than half the responses were at least modeled to a moderate degree. Overall, there is no indication that one or more of the categories is being ignored and evidence that there is some modeling throughout all the categories. 


\section{Table 7}

Percentages of standards modeled, by category

Means of standards modeled

Categories

less than 2.7

2.7-3.3

more than 3.3

\begin{tabular}{lccc}
\hline I.Technology operations and concepts & $18 \%$ & $65 \%$ & $18 \%$ \\
II.Planning and designing learning & & & \\
$\quad$ environments and experiences & $50 \%$ & $50 \%$ & ----- \\
III.Teaching learning and the curriculum & $20 \%$ & $67 \%$ & $13 \%$ \\
IV.Assessment and evaluation & $58 \%$ & $25 \%$ & $17 \%$ \\
V.Productivity and professional practice & $21 \%$ & $53 \%$ & $26 \%$ \\
VI.Social, ethical, legal, and human issues & $58 \%$ & $42 \%$ & ------ \\
\hline
\end{tabular}

Note. Totals may not add to $100 \%$ due to rounding.

From Table 8 we can see that in categories II and VI no faculty report requiring proficiency of their students at a high degree. Again, it should be noted that no general performance standards were placed by ISTE into category II so that column is only based on professional standards. In category VI there was an even split between low and moderate, and in categories I,II,III, and $\mathrm{V}$, the moderate grouping was chosen a higher percentage of the time. Overall, based on observational assessment of the means, there was no indication that one or more of the categories is being ignored and almost all categories indicate that faculty reported requiring students to exhibit proficiency to at least a moderate degree a majority of the time. 


\section{Table 8}

Percentage of standards required, by category

Means of standards required

Categories

less than $2.7 \quad 2.7-3.3$

more than 3.3

\begin{tabular}{lccc}
\hline $\begin{array}{l}\text { I.Technology operations and concepts } \\
\text { II.Planning and designing learning }\end{array}$ & $24 \%$ & $59 \%$ & $18 \%$ \\
$\quad$ environments and experiences & $25 \%$ & $75 \%$ & ----- \\
III.Teaching learning and the curriculum & $27 \%$ & $60 \%$ & $13 \%$ \\
IV.Assessment and evaluation & $50 \%$ & $33 \%$ & $17 \%$ \\
V.Productivity and professional practice & $21 \%$ & $58 \%$ & $21 \%$ \\
VI.Social, ethical, legal, and human issues & $50 \%$ & $50 \%$ & ------ \\
\hline
\end{tabular}

Note. Totals may not add to $100 \%$ due to rounding.

After the initial examination of means for each category, a Pearson productmoment correlation was calculated for scores modeled and required within each of the categories. All the calculated values exceeded the critical value of $r$ at $p<.05$ and ranged from .77 to .92 , indicating a strong correlation between the modeled and required standards in each category (see Appendix F).

\section{Survey Part II}

\section{Descriptive Analysis}

In this section, a number of questions were asked regarding teaching responsibilities and experiences. Faculty responses to these questions were entered and analyzed using descriptive statistics and frequency distributions. Results of this analysis are presented below.

The population was defined as faculty engaged in an undergraduate program leading to teaching certification. Through the Vermont State Department of Education a list was developed of those colleges which qualified. Then the most current catalogues from each college were obtained to develop a list of those faculty who taught in the departments of education. This information was augmented, when possible, through the 
web sites of each college. This list led to surveys being sent to nine colleges, three state schools with 18 faculty, four private schools with 19 faculty and one state university with 32 faculty. Of those responding, private and state colleges groups each had eight and there were sixteen from the university. In other words, $41 \%$ of the population from private colleges responded, $42 \%$ from the state institutions, and $47 \%$ from the university.

The initial questions posed involved teaching experiences. First, faculty were asked the number of years they had taught in higher education. Their answers ranged from 3 years to 37 years, while most of them (56\%) fell between 10 and 20 years. Next, faculty were asked about the number of years they taught elementary through high school, if applicable. The replies ranged from 1 to 26 . Most of these (52\%) fell between 5 and 10 years, with three faculty indicating no experience at that level.

When asked what course(s) they were teaching, most faculty listed one to three courses, but some included all courses which they had ever taught, while a few gave general statements about courses (elementary level methods courses). Courses included methods, classroom management, assessment, disabilities, history and administration. Only 3 faculty members listed courses which were directly linked to technology skills. Of those, as would be expected, all rated their computer skills as advanced. The only respondent whose self-rating was expert (5) listed educational foundations, introduction to education, educational psychology and reading in content areas as courses taught. The one faculty member whose self-rating was novice (1) reported teaching science and math methods, along with adolescent development.

The next two questions involved technology knowledge. When asked to rate their own computer skills, respondents chose from five categories: novice, beginner, intermediate, advanced, and expert. For the purpose of data entry, these categories were numbered from one to five, with one being novice and five being expert. Most respondents chose either intermediate $(44 \%)$ or advanced $(28 \%)$. The mean of the responses was 3.22. Only one each said 1 (novice) or 5 (expert).

Following their assessment of their own skills, faculty were asked whether or not the ISTE standards were required in their institutions. Although the standards were reported to be modeled and required at least to a moderate degree by most of the faculty, $47 \%$ said they were not required at their schools, only $22 \%$ said they were required and $22 \%$ said they didn't know or weren't sure. In the university, the school with the largest number of respondents, the faculty responses were evenly divided 
between yes, no and don't know, even though their program had been involved with a grant to train faculty to use technology, based on the ISTE standards.

\section{Statistical Analysis}

To determine if there was any correlation between the degree of modeling and requiring of the standards and the demographic questions, two types of statistical analysis were administered. For the years teaching in higher education, the years teaching in K-12 settings, and the self-rating of computer skills, the data was dealt with as continuous and therefore Pearson product-moment analyses were conducted, with an alpha of 0.05 (see Appendices $F, G$ ). The first question related to the years the faculty member had spent teaching in higher education institutions. When calculated by the degree to which they modeled the standards, only in one instance did the calculated score exceed the critical score, and that was -.37, indicating a weak negative correlation. When compared to the degree to which they required the standards, only $6(15 \%)$ exceeded the critical value. They ranged from -.37 to -.41 , also indicating a weak, negative correlation.

The second question asked about the years the faculty member may have taught in $\mathrm{K}-12$ settings. When compared with the standards modeled, only 6 had a calculated score exceeding the critical values. They ranged from .38 to .44 , indicating a weak, positive correlation. When compared to the standards required, $19(46 \%)$ of the calculated values exceeded the critical values. They ranged from .35 to .50 , also indicating a weak, positive correlation. They were spread throughout the standards, showing no strong trend or type of standard reported.

The third demographic question which could be considered continuous was how the faculty member rated his/her own computer skills. When compared with standards modeled, in 27 of 41 standards (66\%) the calculated value exceeded the critical value. It was found that $37 \%$ of those were above .50 , indicating a moderate correlation, while $10 \%$ were above .61 , indicating a strong correlation. When compared with standards required only 9 , or $22 \%$, showed a statistical correlation. Only three of these were in the general profile, while the others were spread throughout the professional profile. Also, none were more than .50 , indicating that the correlations were not strong.

Since the type of college and the yes/no for ISTE requirement at the college are nominal data, contingency tables and chi squares were the appropriate statistics . Initial 
analysis was computed using raw scores, but since the respondent pool was small, the numbers in the contingency table cells were low and therefore suspect. In order to ensure that the contingency tables would be more robust and the information garnered would be more useable, the college affiliation was grouped in two ways. First, by type (private, state or university) and then by size (small, large). These grouped responses for the demographic questions were compared with the grouped responses for modeling and requiring each standard. Results of each analysis are found in Appendix L, for standards modeled, and in Appendix L, for standards required.

\section{Table 9}

Results of contingency analysis on individual standards, by demographic questions.

\begin{tabular}{|c|c|c|c|c|}
\hline \multirow[b]{2}{*}{ Demographic question } & \multicolumn{3}{|c|}{$\begin{array}{l}\text { Number of standards } \\
\text { Showing statistical significance }\end{array}$} & \multirow[b]{2}{*}{$\begin{array}{l}\% \text { sig of } \\
\text { all standards }\end{array}$} \\
\hline & modeled & required & $\begin{array}{c}\text { total of } \\
\text { sig. standards }\end{array}$ & \\
\hline College - state,private, univ. & 2 & 7 & 9 & $11 \%$ \\
\hline College - small,large & 5 & 4 & 9 & $11 \%$ \\
\hline Standards required & 5 & 9 & 14 & $17 \%$ \\
\hline
\end{tabular}

Table 9 indicates that out of 82 possible responses for each demographic question (both modeled and required) there was little statistical significance at the conservative $p<.05$ level, between the standards and the demographic questions.

As described in Table 6, along with defining specific standards for preservice students, ISTE developed broad categories into which each standard was placed. Using these categories not only might determine if significance would be demonstrated by regrouping the data, it also helps to clarify the information gathered from a large, apparently disparate list of standards. Therefore, each demographic question was compared to each broad category.

For those questions with results which can be viewed as continuous, Pearson product-moment correlations were calculated, with an alpha of 0.05 (see Appendix L). First the categories were calculated against the responses to the standards modeled and the standards required. The calculated values all exceeded the critical values and 
ranged from .77 to .92 , indicating a high, positive correlation. Next, the categories were calculated by how the faculty rated their own computer skills. Out of eleven calculated values, seven exceeded the critical values, ranging from .37 to .63 , indicating a moderate correlation. When the categories were calculated against the number of years reported teaching in higher education, the calculated values only exceeded the critical values in 4 instances, and ranged from - .35 to - .40 . This indicated a weak, negative correlation. The last question asked for the years the faculty member may have taught in $\mathrm{K}-12$ settings. There were 8 calculated values which exceeded the critical values, and they ranged from .35 to .48 , indicating a weak, positive correlation.

For those questions generating ordinal data, calculations were made using contingency tables with a $p<.05$ (see Appendix $L$ ). In most of these contingency tables the correlation was not statistically significant. There were only 6 instances (of 66 assessments made) in which the contingency tables showed a significant relationship between the demographic questions and the categories. That $11 \%$ represented standards which were spread throughout the categories, and were not indicative of a trend or area needing further attention.

\section{Open-ended Questions}

In addition to the directed questions in the survey, respondents were given an opportunity to relate obstacles to the integration of technology into their programs or support they have received in the use of technology in their institutions. Out of all respondents, $75 \%$ offered their opinions and shared their experiences, relating 46 different comments, both positive and negative. Overall, $45 \%$ of the comments were about support given through their institute, and were sorted into three categories general support, access to hardware, and technical support. For example:

"Yes, very helpful support in my college. If I ask, I receive."

"The college provides us laptops to facilitate integration"

"access to network and computers with wireless network and laptop module cart facilitate integration"

"... had a student mentor help me code my syllabus."

The obstacle mentioned most frequently was the lack of time the faculty member felt was available for learning to use the new technology (20\% of complaints). Comments also included concerns about time to learn new applications, prepare 
lessons, and integrate these into the curriculum. This was not necessarily seen as an institutional issue, as in:

"...I need to find the time to integrate it with my courses"

"I know I should be doing much more to model...I need to find the time to integrate it with my courses"

but it was noted as a problem when trying to fit new skills into an already busy schedule.

One respondent added that:

"People should be given professional development leave to learn new technology. I have no time for this and so I'm falling further and further behind."

Need for access to hardware was mentioned, as in the comments:

"...we don't have hardware to be able for all faculty to use on a regular basis..."

" we have no computer lab in the building where the major portion of my classes are taught"

"I need to model more in class but we don't have hardware to be able for all faculty to use on a regular basis."

"need more readily available equipment, e.g.-digital videocam.

Respondents also mentioned problems with funding, as in:

"not enough funding to keep current in technology resources and most current hardware"

"lack of funding to purchase software"

One other problem mentioned was lack of technical support:

"lack of institutional \$ for ... tech support"

"need more on-going ... training."

"need more support from techies:

At the end of the survey, respondents were given the opportunity to offer additional comments. There were only a few who took advantage of this, and their comments ranged from:

"At my stage of career I do what I have to do with technology but I expect and encourage my students to do more - they after all, are the future!" to "...technology does not excite me...I have found most programs and applications tedious to learn..."

In total, $67 \%$ of the comments referred to obstacles to the integration of technology, while $33 \%$ reported ways in which the institution assisted faculty through general or specific support. 


\section{Chapter Five}

Summary, Implications and Recommendations

The purpose of this research was to determine the degree to which faculty who teach preservice teachers report adherence to nationally known technology standards for students enrolled in teacher preparation programs. In the first two chapters, the spread of computer use in all levels of education has been documented. Since there is continued growth of computer use in schools, it is necessary for teachers to not only have those skills, but be able to use them in their classrooms and assist their students in honing their own skills. The International Society for Technology in Education (ISTE) has developed a set of standards for K-12 students, their teachers, and for those students in teacher preparation programs. These standards have been adopted by the National Council for Accreditation of Teacher Education (NCATE) and by forty-two states. Vermont expects new teachers and those seeking recertification to refer to those same standards when applying for licensure. Data revealing the extent to which these standards are used by the faculty in certifying schools in Vermont had not been gathered directly from the faculty. ISTE questioned the Vermont State Technology Coordinator about standards required by the state. Most national studies address their questions about faculty use to the technology coordinators (Green \& Eastman,00, \& Solomon \& Wiederhorn, 99). This research was designed to gather information directly from the faculty about their teaching methods and technology use.

Chapter three described the methods used to gather data regarding the degree of the correlation between faculty reported modeling of the ISTE standards and faculty reported requirements of their students regarding the ISTE standards, while chapter four depicted the findings from the gathered data. Faculty were asked to what degree they modeled each standard and to what degree they required their students to exhibit proficiency in each standard. They were given a Likert-type scale and the direction to choose a number along a continuum of degree, with one being to a limited degree and five being to a great degree. They were also asked to respond to a set of short answer and open ended questions regarding their teaching practices and opinions. 
Survey, Part I

Question One: Faculty were asked "To what degree do you model" each standard. The means of their responses were calculated, and these ranged from 2.0 to 4.0. As reported in Chapter Four, 37\% of the faculty's choices were at 3 or more, and none of the faculty reported that the standards did not apply to their courses. Therefore, faculty reported at least some modeling of all of the standards.

After reviewing frequency tables and means, in order to more clearly describe the responses, the means were condensed into three groups: low = less than 2.7, moderate $=2.7-3.3$, and high $=$ more than 3.3. The results (see Table 2 Chapter Four) indicated that faculty report their modeling of standards to be evenly split between low and moderate, with almost one-fifth of the respondents reporting a high degree of modeling.

The ISTE standards were developed for K-12 students, K-12 teachers, education students, first-year teachers, and classroom teachers. Each set of standards has its own subset of skills and experiences, which can be used by teachers, faculty and education students to make sure that the appropriate areas are being covered. In order to address all the standards which should be met by students before their student teaching experience, both general and professional standards had been included in the questionnaire. Even though there is some overlap in the subsets, differences in the degree to which faculty modeled these two sets of standards could offer information about technology standards which may be neglected in the programs for education students. Therefore, results were separated into general (standards 1-17) and professional (standards 18-41). General standards are those presumed achieved early in the students' educational career, while professional standards should be mastered before student teaching is begun. It appears (see Table 2, Chapter 4) that general standards were modeled more of the time either to a low (47\%) or high degree (35\%), but almost $20 \%$ of the means were reported as moderate. That is, there is a fairly even spread of the extent of modeling from low to high degree. Professional standards, on the other hand, were rarely modeled to a high degree $(4 \%)$, but reported means were higher in the moderate than in the low grouping. That is, faculty primarily reported modeling professional standards (those met later) moderately. Initial descriptive analysis indicates that this may be an area which faculty would want to address more strongly. 
Question Two: Faculty were asked "To what degree do you require students to be proficient" in each standard. The means of their responses were calculated, and these ranged from 2.0 to 3.9. As reported in Chapter 4, 34\% of the faculty's choices were at 3 or more, and none of the faculty reported that the standards did not apply to their courses. Therefore, faculty reported requiring the standards at least to some degree. Frequency tables and means of standards required were reviewed and, in order to more clearly describe the responses, the means were condensed into three groups: low $=$ less than 2.7, moderate $=2.7-3.3$, and high $=$ more than 3.3. The results (see Table 3, Chapter 4) indicated that $51 \%$ of faculty report requiring students to be proficient in standards to a low degree, and only $10 \%$ report requiring standards to a high degree.

In dealing with this question, as in the question of modeling, responses were split into the two sets of standards, general and professional. Table 3, Chapter 4 shows that the general standards were required more frequently (53\%) to a low degree, but were required by almost one-quarter of the respondents to a moderate degree and almost one-quarter to a high degree.

That is, they did report that they required those standards students were responsible for earlier in their educational careers. For professional standards, the difference is more dramatic. There were no standards which were reported to be required to a high degree. In other words, faculty required students to show proficiency in standards deemed necessary immediately prior to student teaching only to a low or moderate degree. Again, initial descriptive analysis indicates that increased attention may be needed to the area of professional standards.

Question Three: Using descriptive methods, the means for the degree each standard was reported as being modeled were compared with the means for the degree each standard was reported as being required (see Appendix E). It was found that out of 41 means 21 (50\%) were reported as being a higher degree for modeling than for required, 18 were rated lower and two were equal. When these were separated into general and professional categories, it was found that faculty were more likely to model than require general standards ( 12 out of 17) and more likely to require than model professional standards (14 out of 23). Therefore, faculty report modeling standards students acquire earlier to a higher degree and requiring those they acquire later to a high degree. 
As in the earlier analysis of modeling and requiring, the means were split into three groups, low (less than 2.7), moderate (2.7-3.3) and high (more than 3.3). In summary, the results suggest the reported degree of modeling and the reported degree of requiring show only slight differences.

To augment the observational data and determine if the apparent differences had statistical significance and if so, what those differences might be, t-tests were run on the modeled and required means, with the level of significance set at $p<0.05$. The results showed that only two standards showed statistically significant differences between modeled and required standards (see Appendix E). Although they both relate to collaborative use of technology, there are other standards which include similar skills and knowledge and were not found to be statistically different. Therefore, it is not a strong indication of a trend or area to pursue further.

Since the research question asks for the correlation between the reported degree of modeling the standards and the reported degree of requiring the standards of the students, a Pearson product-moment correlation was calculated, with an alpha of $p<0.05$ (see Appendix L). Analysis of the results found that all calculated values exceeded critical values, and ranged from .77 to .92 . This indicates a strong, positive correlation. In other words, faculty appear to practice what they preach - they model what they require. Specifically, $68 \%$ of the values were at .81 or higher. This finding agreed overall with observational data and the t-test results, which showed that the faculty reported modeling and requiring to a similar degree. That is, the degree to which they modeled the standards was statistically similar to the degree to which they required the standards. When the results were divided into the general and professional profiles, it was found that only while $47 \%$ of the values were above .81 in the former, $88 \%$ of the values were at or above .81 in the latter. That is, the faculty showed a higher correlation in their reported responses to those standards the students need to master later in the educational program.

Thus far, the analysis had looked at all the standards individually and found few differences between the degree to which faculty reported modeling and requiring those standards to their students. In order to see the data in ways which would be clearer to those who might make use of the results, it was decided regroup the standards into the six general categories developed by ISTE and see if this would allow any patterns to emerge. 
When developing their technology standards, ISTE produced a list of six broad categories which were to be used by educators as a framework planning technology-rich environments. Each of the standards listed in the questionnaire had been placed by ISTE into one or more categories. Since the categories are broad there is often more than one category into which a particular standard can be placed. For example, standard 8 - use technology tools to process data and report results - has been placed by ISTE in categories I,III,IV and V. Therefore the number of standards per category will be more than the total number of standards. The categories ISTE defined are defined in Chapter 4, Table 6.

A comparison of Tables 7 and 8 in Chapter 4 shows that categories I (technology operations and concepts), III (teaching, learning and the curriculum) and V (productivity and professional practice) appear similar in the distribution of the means. That is, they all show the majority of the faculty reported modeling and requiring to a moderate degree and a little less than one-quarter of the faculty reporting was split between both high and low degree. Category II (planning and designing learning environments and experiences) represents only professional standards and for both modeling and requiring the means were not over 3.0. Even though category VI does include both general and professional standards, it too had means which did not exceed 3.1. This category deals with social, ethical, legal and human issues involving technology and the results may indicate an area in which more attention should be paid.

\section{Survey, Part II}

\section{Demographic Data}

There had been additional data gathered through the survey along with the two questions about standards. These included questions asked directly and data determined from the survey indirectly. Respondents had been asked to report what courses they were teaching, the number of years they had taught in higher education and, if applicable, the number of years they had taught in K-12 settings. Then they had been asked to rate their own computer skills by circling the most appropriate word from a list of five terms: novice, beginner, intermediate, advanced and expert. Along with the information gathered directly from the respondents was a factor culled from the data gathering process. Each questionnaire was numbered before it was mailed so that the intended recipients could be recontacted if necessary, which then supplied information 
about college affiliation of the respondents. This information, along with the directly gathered data, was then used in analyses to determine if there were significant factors which could be correlated with technology use by education faculty.

The population had been defined as faculty engaged in an undergraduate program leading to teaching certification. In total, there was a response rate of $46 \%$. Of those responding, $41 \%$ of the population from private colleges responded, $42 \%$ from the state institutions, and $47 \%$ of the university.

When asked the number of years they had taught in higher education their answers ranged from 3 years to 37 years, while $56 \%$ of them fell between 10 and 20 years. When asked about the number of years they taught elementary through high school, if applicable, their replies ranged from 0 to 26 years, with $52 \%$ between 5 and 10 years.

When asked to rate their own computer skills, respondents chose from five categories: novice, beginner, intermediate, advanced, and expert. For the purpose of data entry, these categories were numbered from one to five, with one being novice and five being expert. Most respondents chose either intermediate (44\%) or advanced (34\%). The mean of the responses was 3.22. Only one each said 1 (novice) or 5 (expert). If these self-assessments are accurate, then the majority of respondents have some or many of the skills needed to model the standards and to understand what should be required of the preservice student.

When faculty were asked what courses they taught they offered a wide range of responses, including introduction to education, methods classes, administration, and special education. There were three respondents who taught computer-related classes, and all of them rated their computer skills as advanced. The only respondent whose self-rating was expert (5), listed educational foundations, introduction to education, educational psychology and reading in content areas as courses taught. The one faculty member whose self-rating was novice (1) reported teaching science and math methods, along with adolescent development. Some of the responses were general (I teach a variety of courses, I have taught a complete range of courses) and some listed all the courses they ever taught. Without a clear split between courses which, by their content, would be technology-related and those which would not, the results of this question can only be reported anecdotally.

Faculty were asked whether or not the ISTE standards were required in their institutions. The largest group said no (47\%), 31\% said yes and $22 \%$ said don't 
know/not sure. In the university, the faculty responses were evenly divided between yes, no and don't know. When these responses were compared with colleges and the ways in which faculty rated their computer skills using contingency tables the analysis showed no significant relationship. It is interesting to note that the state of Vermont now requires new teachers and those relicensing to meet these standards (Vermont State Department of Education,n.d.). It may be that the colleges share that information with their students and expect them to be responsible for meeting the state requirements, without the college formally requiring the students to conform to the ISTE standards. It is also possible that some institutions use different terminology to define the standard. Since this was a self-administered questionnaire, it was not possible to know how each school labeled their requirements.

\section{Open ended Questions}

Initial assessments looked at the results available from analysis of the data gathered from the questions about modeling and requiring standards, using a variety of approaches (observation, grouping, t-tests, chi-squares). Additional assessments were then done to determine if the demographic data gathered would indicate any trends or patterns not evident from the previous analyses.

Statistical analyses applying Pearson product-moment correlations and contingency tables were completed using the demographic data and responses of faculty to the questions : to what degree do you model the standards, and to what degree to you require the standards. Correlations were calculated on those questions producing results which could be viewed as continuous. These included how the faculty rated their own computer skills and the number of years they reported teaching in higher education and in K-12 settings (see Appendices F,G). Findings indicated that the only demographic question in which a majority of standards correlated with either question was how faculty rated their own computer skills when compared with reported faculty responses to standards modeled $(66 \%)$. When the level to which they rated their own skills was compared with the standards they required of their students, the results show only $22 \%$ of calculated values were above the critical values. It is logical that a person's skill will positively correlate with what the person will model, but it is curious to see that this does not correlate as strongly with their expectations of their students. It is possible that this is due to faculty opinions of their students capabilities, or of the skills they 
expect their students to need in the future. It is also interesting to note that, although there were only 7 standards which correlated significantly with the number of years faculty reported teaching in higher education institutions, the correlation was negative, indicating that the longer they taught, the less they modeled or required technology standards.

The other demographic information, in what type of college did the faculty teach and did that college require the ISTE standards, resulted in ordinal data and the appropriate assessment to determine relationship between sets of ordinal data is the chisquare test. These responses were then analyzed using chi-square contingency tests to determine if there was a significant relationship between the demographic data and the degree to which the standards were modeled or required (see Appendices $\mathrm{H}, \mathrm{I}$ ). For all the statistical tests, the level of significance was set at the $p<.05$ level.

Table 9, Chapter 4 shows that there was little statistical significance between the standards and most of the demographic questions. Those standards which showed significance did not indicate any patterns or trends. This suggests that the type of college and knowledge that the institution required ISTE standards do not have a strong relationship with the degree to which faculty report modeling or requiring the ISTE standards.

The broad categories into which ISTE had grouped the standards were used to assess whether or not restructuring the data would point up any trends and to facilitate the use of the data. These broad categories were designed by ISTE to be used as the basis for developing a technology-rich educational environment.

Each of these grouped standards was analyzed through Pearson productmoment correlations (for continuous data) and contingency tables (for ordinal data) by each of the demographic questions. Using the Pearson product-moment correlation, when modeled categories were calculated with required categories, all calculated values exceeded the critical values, with results ranging from .77 to .92 (see Appendix $L$ ). This indicated a strong, positive correlation, which agreed with results from analyses done on individual standards. That is, the faculty were consistent about the degree to which they reported modeling and requiring the standards.

When calculated for how faculty rate their own skills by the degree they reported modeling the standards, the results for all the categories demonstrated a positive correlation, with calculated values ranging from .48 to .63 . When compared to the degree to which the faculty reported requiring the standards, there were only three 
results in which the calculated values exceeded the critical values. This result mirrors that of the analysis done on individual standards. Here again, faculty are reporting that their rating of their own computer skills correlates more strongly with the degree to which they model the standards than the degree to which they report requiring the standards.

Correlation was also calculated on the number of years faculty taught in higher education. None of the standards modeled correlated with this question and only four of those required were correlated. These showed a weak (.35 to .40) negative correlation. That is, the longer the faculty member reported teaching in higher education, the less they required the standards of their students. This result was not repeated in the question involving years teaching in $\mathrm{K}-12$ settings. There, although only one category showed a correlation to the reported modeling of the standards, it was positive, and there were seven results (two general and five professional) in which there was a positive correlation. These were also weak (.36 to .48), but they do indicate that the longer the faculty had spent teaching in a K-12 setting, the higher the degree that respondent reported requiring the standards of their students. This could indicate that direct experience in the $\mathrm{K}-12$ classroom raises awareness of specific skills which teachers need.

The questions resulting in ordinal data were analyzed using contingency tables. Again, for each chi-square, the level of significance was set at $p<0.05$. In most of the contingency tables (89\%) (see Appendix L) the correlation again did not prove to be statistically significant. When looking at those standards which showed significant correlation, no discernable patterns could be determined. When each category was run against each other category all were significantly related, with the highest degree of relationship in the professional rather than general groupings. This indicates that categories, although they may cover different skills and experiences, are reported to be either modeled or required to a similar degree.

The last two questions asked of the respondents were in an open-ended format. They were to record support for and/or obstacles to the integration of technology in their college courses. Out of a total of forty-six comments, $31(67 \%)$ reported obstacles and $15(33 \%)$ reported support. The largest number of comments, $28 \%$, noted problems with access to equipment as being an obstacle. Their concerns were for a greater spread of technology across campus, as well as continued updating of equipment. Although many of the faculty noted their colleges' support (21\%), there were $20 \%$ who found no time to learn new material or incorporate new skills. 
Implications:

1. The primary goals of this study were to determine the degree to which faculty modeled and required the ISTE standards and the correlation between the degree to which faculty modeled ISTE standards and the degree to which they required their students to exhibit proficiency based on the ISTE standards for students. In reviewing the findings of the variety of statistical assessments which were made, the majority of the faculty report that they model $(83 \%)$ and require $(90 \%)$ ISTE standards at a low to moderate degree. That is, for each standard, the faculty responding to the questionnaire reported that they did model the use of the standard and require that their students also use technology as stated in the ISTE standards, but most of them did not report using $(17 \%)$ or requiring $(10 \%)$ technology to a high degree.

The findings also indicate that there was no significant difference between the rate they report modeling the standards and the rate they report requiring their students to show proficiency in these standards. In other words, the faculty did not require the students to attend to the standards to a higher degree than the faculty were willing to model. Actually, when looking at the means for each standard modeled and each standard required, there were more instances (21) in which the degree modeled was higher than the degree required (there were also 2 in which the means were equal) (see Appendix L). However, when looking at Tables 7 and 8 in Chapter 4, it is notable that in category II - planning and designing learning environments and experiences - faculty do not report modeling or requiring to a high degree. This is an area which is of great import to students about to enter their first student teaching experiences. The lack of faculty reporting the inclusion of that area in their curricula to a high degree is an indication of an issue which should be explored. Oppong (1997) found that when technology is integrated into the curriculum it is more effective in raising student awareness of the value of technology in education. Others (Zhang \& Espinoza, 98; Halpin, 99) also found that including technology in the curriculum benefited preservice students. In 1997, Kahn found few faculty modeling strategies for the use of technology, while a study by Stevens (2000) indicated that modeling the use of technology by faculty was strongly correlated to preservice students' use of technology.

2. The secondary goal of the study was to determine if there was any correlation between the demographic information gathered from the additional questions and the 
distribution information, with the responses to the questions about the use of the ISTE standards. Overall, there was little significant correlation; that is, the teaching history of the faculty did not seem to relate to their reported modeling or requiring of the standards (see Appendix L).

In general, these results can be interpreted as a positive finding for the students and faculty at the institutions studied. Since the students will need to use the standards to get licensed in the state (Vermont State Department of Education, n.d.), it is reassuring to know that these standards are being addressed in their education programs. For faculty, it is reassuring to know that within their education programs there are faculty who report addressing the newly adopted state wide set of standards. It is also reassuring to know that, of the faculty responding to the questionnaire, neither the number of years teaching nor the type of college correlated to the faculty members responses to the two questions about the standards, indicating that the use of technology was spread throughout the programs. In other words, use of technology was spread among those faculty with varying numbers of years of teaching experience and among all colleges surveyed. There was a correlation with the reported rating of their own skills, which indicates that there was consistency within their responses. That is, those who stated that they were more experienced used or required the standards to a higher degree than those who reported lower skill levels.

It is possible that the faculty participating in the survey were those who are generally positive about and users of technology, and that if all had participate the degree of modeling and/or requiring would have been lower. Even if this is true, the needs of the students will be met as long as there are some faculty in each institution who are involved in the modeling and requiring of the ISTE standards. The findings from this research offer empirical validation of the likelihood that students in schools of education will be able to gain the technology skills they need.

When responding to the open-ended question regarding support or obstacles to the use of technology, 67\% referred to obstacles. Adams (2002), in a study of postsecondary faculty, found that availability of software and hardware and limited training for faculty and students were of concern to more than $30 \%$ of respondents. In this study, time available to learn how to use the new technologies was mentioned most (20\% of the comments)., but access to hardware and software were also of concern (28\%). O'Bannon $(1997,1998)$ also found limited access to technology and a lack of administrative support. When this is seen in the light of research affirming the need for 
authentic experiences for preservice teachers (Dawson and Noris, 2000), it points to the need for institutions to meet the needs of faculty and students so that technology skills which are required can be acquired.

On October 1, 2002, ISTE released an updated list of states which had adopted, adapted or referenced at least one set of NETS (National Educational Technology Standards) for students, teachers and/or administrators (International Society for Technology in Education, 2002). Of the 42 states included, 40\% identified administration standards, 57\% indicated student standards and 64\% checked off teacher standards. Vermont was recorded as referencing teacher standards. This means that new teachers and those applying for relicensure must document their technology skills by referring to the ISTE standards.

In the Regulations Governing the Licensing of Educators for Vermont, there are updated guidelines for new and relicensing educators. In 1998, there were just general technology skills mentioned. According to principle \#9 of the revised Five Standards for Vermont Educators (2002), "Quality is indicated when an educator ... is familiar with the National Educational Technology Standards for Teachers... and uses them to guide and assess his/her efforts to integrate technology into the teaching and learning process ". It is now necessary for students in teacher preparation programs to provide those evaluating them for certification with a portfolio which addresses the ISTE standards along with the standards in their specific fields.

These changes in Vermont, as well as in the standards adopted, adapted or referred to by the other 41 states, indicates an acceptance of the ISTE standards across the country. It is therefore important to know how available the information and skill training is for education students.

\section{Recommendations:}

The information gathered from this research can be used by faculty and administrators to assess how institutions in the state fared as to the reported integration of technology in the field of education. As with all research, there were limitations to this study. Overall, since this was a small study, additional data would be useful to determine if the findings are true for the rest of the state. Also, since it is based on a self-report, observation or interviews would broaden the use of the data gathered. 
Because of these limitations, there are areas for further research which should be addressed. They include:

a. determining if there is adequate support in the colleges for the faculty to develop appropriate uses of technology in their curricula. This concern is based on statements made by the faculty in this study, as well as studies noting access , support, time and money as issues raised by other faculty (O.Bannon, 97; Vannetta \& Beyerbach, $00)$.

b. determining if students are perceiving that the faculty are modeling and/or requiring the standards the students need to meet. Topp (1996) found that modeling by faculty would have been useful, but having faculty model and having students gain from this experience needs more documentation. Additional research would help in finding out what are the best methods of addressing the students' concerns.

c. determining if the college offers other venues, outside of the education program, for the students to learn and practice their technology skills; determining if these other venues are useful to students when integrating technology into educational tasks.

d. determining if the schools in which the students practice their skills have adequate materials and mentors for the students to hone their skills; determining if the colleges should develop partnerships to increase the use of technology, if necessary. Wetzel, Zambo, Buss and Arbough (1996) found students' experiences limited by the technology limits in their receiving schools.

In conclusion, this study documented that faculty at schools of education in Vermont who responded to the survey reported that they did model and/or require the ISTE standards. According to a recent ITEA/Gallup poll (Rose \& Dugger, 2002) "There is near total consensus in the public sampled that schools should include the study of technology in the curriculum (p.1)." There is also nationwide acceptance by state departments of education of technology standards for students and teachers (ISTE, 2002). This research therefore provides information that increases the breadth of existing knowledge. confirms previous studies, and is a useful addition to the literature on teacher education programs. The findings can be used by administrators assessing their colleges' needs, by faculty comparing their institution with others, and by all those involved with technology training in $\mathrm{K}-12$ or higher education. 


\section{References}

Abbot, A., \& Faris, S.E. ( 2000). Integrating technology into preservice literacy instruction: A survey of elementary education students' attitudes toward computers. Journal of Research on Computing in Education, 33, 149-161.

Achleitner, H., Vowell. F. \& Wyatt, R. (1995). Repackaging and recycling: Using information technology to enhance education in the present and the future. Proceedings of the 1995 CAUSE Annual Conference, 6-2-1 to 6-2-10.

Adams, N.B. (2002). Educational computing concerns of postsecondary faculty. Journal of Research on Technology in Education, 34, 285-303.

Alfaro, R. (1999). The technology-reading connection. Educational Leadership 56, (6) 48-50.

Algozzine, B., Bateman, L.R., Flowers, C.P.,Gretes, J.A., Hughes, C.D., \& Lambert, R. (1999, September 8). Developing technology competencies in a college of education. Current Issues in Education 2 (3). Retrieved November 9, 2002, from http://cie.ed.asu.edu/volume2/number3/.

Beichner, R.J. (1993). Technology competencies for new teachers: Issues and suggestions. Journal of Computing in Teacher Education, 9, 17-20.

Berg, S., Benz, C.R., Lasley, T.J., Raisch, C.D. (1998). Exemplary technology use in elementary classrooms. Journal of Research on Computing in Education, 31, 11122.

Bernard, H.R. (2000). Social research methods: Qualitative and quantitative approaches. Thousand Oaks, CA:Sage Publications.

Black, T.R. (1999). Doing quantitative research in the social sciences. London, England: Sage Publications.

Bossert, P.J. (2001, November). Lessons learned: An inside look at four of the top technology school districts in the nation. T.H.E. Journal 29 (4), 62-67.

Cherup, S., \& Linklater, L. ( 2000). Integrating technology into preservice education: A model implementation at a small liberal arts college. Journal of Computing in Teacher Education, 16, 18-22.

Chiero, R.T. (1997). Teachers' perspectives on factors that affect computer use. Journal of Research on Computing in Education, 30, 133-145. 
Creswell, J.W. (2002). Educational Research:Planning, conducting, and evaluating quantitative and qualitative research. New Jersey:Merril Prentice Hall.

Dawson, K., \& Norris, A. (2000). Preservice teachers' experiences in a K-12/University technology-based field: Benefits, facilitators, constraints, and implications for teacher educators. Journal of Computing in Teacher Education, 17, 4-12.

Dewert, M. H. (1999). The times they are a-changin': A look a technology-related requirements for teacher licensure and certification. Journal of Computing in Teacher Education, 13, 4-6.

Dusick, D. M. (1998). What social cognitive factors influence faculty members' use of computers for teaching? A literature review. Journal of Research on Computing in Education, 31, 123-137.

Eastwood, K., Harmony, D., Chamberlain, C. (1998). Technology planning: integrating technology into instruction. Curriculum/Technology Quarterly, 7 (3), 1-4.

Ehman, L.H. (2001). Using stand-alone web modules to integrate technology into secondary social studies methods instruction. Journal of Research in Teacher Education 34, 39-50.

Eisenman, G., Thornton, H. (1999. April). Telementoring: Helping new teachers through the first year. T.H.E. Journal, 26 (9), 79-82.

Fleming-McCormick, T. (1995). Final guidelines and procedures for teacher development systems: Integrating technology and instruction. San Francisco, CA.: Far West Laboratory for Educational Research and Development.

Gordon, D.T. (2002). Curriculum access in the digital age. Harvard Education Letter. Retrieved February 7, 2002, from http://www.edletter.org/pas/.

Green, K.C., \& Eastman, S. (1998). Campus computing 1998: The EDUCOM/USC survey of information technology in higher education. Univ. of Southern CA.: Center for Scholarly Technology.

Green, K.C., \& Eastman, S. (2000). The campus computing project. Retrieved May 4, 2001, from http:// www.campuscomputing.net.

Halpin, R. (1999,). A model of constructivist learning in practice: Computer literacy integrated into elementary mathematics and science teacher education. Journal of Research on Computing in Education 32, 129-138.

Handler, M.G. \& Strudler, N. (1997). The ISTE Foundation standards: Issues of implementation. Journal of Computing in Teacher Education, 13, 16-21. 
Hecht, J. B., Roberts, N. K., \& Schoon, P. L. (1996). Teacher teams and computer technology: Do combined strategies maximize student achievement? Journal of Research on Computing in Education, 28, 318-328.

Higdon, J. ( 1995, March 22-25). The evolution of computer literacy for preservice teachers. Proceedings of the International Conference of the Society for Information Technology and Teacher Education, 310-313.

Hirumi, A., Grau, I. (1996). A review of computer-related state standards, textbooks, and journal articles: Implications for preservice teacher education and professional development. Journal of Computing in Teacher Education, 12, 6-17.

International Society for Technology in Education (2000). National Educational Technology Standards for Teachers. [Brochure]. Eugene, OR. Author.

International Society for Technology in Education (2002, October). National Educational Technology Standards (NETS) and the states. Retrieved October 15, 2002, from http://cnets.iste.org/pdf/states_using_NETS_10_09_02.pdf.

Kahn, J. (1997). Technology-rich teacher education: Meeting the NCATE challenge. Journal of Computing in Teacher Education, 13, 24-29.

Keeler, C. M. ( 1996,). Networked instructional computers in the elementary classroom and their effect on the learning environment: A qualitative evaluation. Journal of Research on Computing in Education, 28, 329-345.

Kerlinger, F.N. (1986). Foundations of behavioral research ( $3^{\text {rd }}$ ed.). New York:Holt, Rinehart and Winston, Inc.

Kukes, I, Dosaj, A., Macdonald, B. (1999, May). The Real Y2K crisis. Technology \& Learning, 19 (9), 27.

Levin, B. B. (1996). Using portfolios to fulfill ISTE/NCATE technology requirements for preservice teacher candidates. Journal of Computing in Teacher Education, 12, 13-20.

Levin, S.G., Buell, J.G., \& Levin, J.A. ( 2000, Spring.). The TEbase Initiative: Research, development, and evaluation for educational reform. Journal of Computing in Teacher Education, 16(3), 6-11.

Malinconico, M. A. (1999, June). Variety is the spice of technology staff development programs. Poster session presented at the annual meeting of the National Educational Computing Conference, Atlantic City, NJ.

Marsh, M. (1999, January) Time for the teachers in your school to "Just do it". Technology and Learning, 19 (5), 60. 
Marcinkiewicz, H.R., \& Wittman, T.K. (1995). Tracking teachers' personal variables and computer use: Phase two. Proceedings of the 1995 Annual National Convention of the Association for Educational Communications and Technology (AECT), 398402.

McGrath, D. \& Thurston, L. (2001-2002,). Long-term follow-up of a computer and gender equity staff development project in rural Kansas. Journal of Computing in Teacher Education 18 (2), 61-67.

Meyer, L. (2001). Technology counts: The new divides. Retrieved November 19, 2002, from http:// www.edweek.org/sreports/tc01.

Mitra, A. (1998,). Categories of computer use and their relationships with attitudes toward computers. Journal of Research on Computing in Education 30, 281-295.

Mitra, A., Steffensmeier, T., Lenzmeier, S. \& Massoni, A. (1999). Changes in attitudes toward computers and use of computers by university faculty. Journal of Research on Computing in Education, 32, 189-202.

Munshi, J. (1990). A method for constructing Likert scales. Retrieved October 17, 2001, from http://munshi.sonoma.edu/working/likert.html.

National Council for the Accreditation of Teacher Education programs, (2000). Professional Standards for the Accreditation of Schools, Colleges and Departments of Education. Retrieved October 5, 2002, from http://www.ncate.org/2000/2000stds.pdf.

Neff, R.K. (1995). The Classroom of the Future. Paper presented at the 1995 CAUSE annual conference, CAUSE, Boulder, CO

O'Bannon, B.W. (1997). Faculty staff development: What is being done and what works. Retrieved June 11, 1999, from: www.coe.uh/insite/elec_pub/HTML1997/fd_ban.htm.

O'Bannon, B. W., Matthew, K. I., Thomas, L. (1998) Faculty development: Key to the integration of technology in teacher education. Journal of Computing in Teacher Education, 14, 7-11.

Office of Technology Assessment (1995). Teachers and technology: Making the connection Washington, D.C.: Congress of the U.S. OTA Report Summary.

Oppong, N. K., Gootman, E., Beckmann, S. (1997). A technology-based exploratory course in geometry for middle school teachers. Journal of Computing in Teacher Education, 14, 16-20. 
Pan, A. C., Lee, D. (1997) Factors that affect preservice and inservice teachers' learning about computers. Retrieved June 9, 1999, from http://www.uno.edu/ edci/site97/site97/htm.

Pannell, P.B.W., Pannell, D.J. (2000). Introduction to social surveying: Pitfalls, potential problems and preferred practices. Retrieved June 11, 2002, from http://www.general.uwa.edu.au/u/dpannell/seameth3.htm

Pederson, J.E., \& O'Dell, J.K. (1993). A survey of current uses of educational technology in science teacher education programs.. (ERIC Document Reproduction Service No. ED 361197).

Petrakis, E. (1996,) Using a portfolio to assess preservice teachers' technology competence. Journal of Computing in Teacher Education, 13, 12-13.

Poole, J. J.; Moran, C. (1998). Schools have their computers, now what? T.H.E. Journal, 2 (5), 60-61.

Pugalee, D. K.; Robinson, R. ( 1998). A study of the impact of teacher training in using internet resources for mathematics and science instruction. Journal of Research on Computing in Education, 31, 78-88.

Rice, M. (1995). Issues surrounding the integration of technology into the K-12 classroom: notes from the field. Interpersonal Computing and Technology: An Electronic Journal for the 21st Century, 3, 67-81.

Robinson, S., \& Milligan, K. (1997). Technology in the mathematics classroom. Journal of Computing in Teacher Education, 14, 11-15.

Ropp, M.M. (1999). Individual characteristics associated with learning to use computers in preservice teacher education. Journal of Research on Computing in Education, $31,402-424$.

Rose, L.C., \& Dugger, W.E. (2002). ITEA/Gallup poll reveals what Americans think about technology. Retrieved May, 13, 2002, from http://www.iteawww.org/TAA/PDF/Gallupreport.pdf

Sall, J., Lehman, A. \& Creighton, L.(2001). JMP start statistics. Pacific Grove, CA: Duxbury Press.

Shenouda, W., \& Johnson, G. (1995). Cooperative efforts to integrate computer technology into teacher education curricula. Proceedings of the Summer Conference of the Association of Small Computer Users in Education (ASCUE) North Myrtle Beach, South Carolina. 
Solomon,LC. \& Wiederhorn, J.A. (1999). Progress of Technology in the Schools: Report on 27 States. Retrieved November 19, 2002, from http://www.mff.org/publications/publications.taf?page=282.

Stevens, G. (2000). An analysis of the instructional use of technological tools by fieldbased preservice teachers. Journal of Computing in Teacher Education, 16, 2832.

Sudzina, M.R. (1993, February). Technology, teachers, educational reform: Implications for teacher preparation. Paper presented at the Annual Meeting of the Association of Teacher Educators, Los Angeles, CA. p. 1-9.

Thomas, J.A., \& Cooper, S.B. (2000). Teaching technology: A new opportunity for pioneers in teacher education. Journal of Computing in Teacher Education, 17, 13-19.

Thurston, C.O.; Secaras, E.D.; Levin, J.A. (1997). Teaching teleapprenticeships: an innovative model for integrating technology into teacher education. Journal of Research on Computing in Education, 29, 385-391.

Topp, N. (1996). Preparation to use technology in the classroom: opinions by recent graduates. Journal of Computing in Teacher Education, 12, 24-27.

Tuckman, B.W. (1988). Conducting educational research ( $3^{\text {rd }}$ ed.). Florida: Harcourt, Brace, Jovanovich.

Vagle, R. (1995). Technology in teaching methods courses: Is it happening? Willis, D. A. and others. Proceedings of the International Conference of the Society of Information Technology and Teacher Education, pp. 238-243.

Vannatta, R. A. (2000). Integrating, infusing, modeling: Preparing technology-using educators. Journal of Computing in Teacher Education, 16, 6-14.

Vannatta, R.A., \& Beyerbach, B. (2000). Facilitating a constructivist vision of technology integration among education and preservice teachers. Journal of Research on Computing in Education, 33, 132-148.

Vermont State Department of Education (n.d.) Vermont post-secondary institutions approved for the preparation of educators. Retrieved February 3, 2002, from http://www.state.vt.us/educ/license/postsec.htm

Wall, R. E., Helfrich, R. C., \& Jones, P. E. (1995, June). The role of computer technology in restructuring teacher education. Poster session presented at the annual National Education Computing Conference, Baltimore, MD. 
Weisenhoff, R., \& Johnson, S. (1998, Fall). Connecting to curriculum goals. Curriculum/Technology Quarterly, 8 (1), 3-4.

Wetzel, D.R. (2001-2002). A model for pedagogical and curricular transformation with technology. Journal of Computing in Teacher Education 18, $43-49$.

Wetzel, K., Zambo, R., Buss, R., \& Arbaugh, N. (1996). Innovations in integrating technology into student teaching experiences. Journal of Research on Computing in Education, 29 , 196-214.

Wiebe, J.H., \& Taylor, H.G. (1997). What should teachers know about technology? A revised look at the ISTE foundations. Journal of Computing in Teacher Education, 13, 5-9.

Wiebe, J.H., Taylor, H.G., \& Thomas, L.G. (2000). The National Educational Technology Standards for PK-12 students: Implications for teacher education. Journal of Computing in Teacher Education, 16, 12-17.

Willis, E.M., \& Sujo de Montes, L. (2002). Does requiring a technology course in preservice teacher education affect student teachers' technology use in the classroom? Journal of Computing in Teacher Education, 18, 78-80.

Wizer, D. (1995,June). The benefits of online education in graduate studies. Paper presented at the National Educational Computing Conference, Baltimore, MD.

Wolk, D. (1998). Regulations governing the licensing of educators and the preparation of educational professionals. Montpelier, VT.:Vermont Board of Education

Wright, V.H., Rice, M. \& Hildreth, D. (2001). Technology growth in an elementary magnet school. Journal of Computing in Teacher Education, 18, 19-24.

Yildirim, Z., Ozden, M.Y., \& Aksu, M. (2001). Comparison of hypermedia learning and traditional instruction on knowledge acquisition and retention. Journal of Educational Research, 94.

Young, J. R. ( 1999, May 28). U. of Washington tries a soft sell to woo professors to technology. The Chronicle of Higher Education. Retrieved May 30, 1999, from http://chronicle.com. section - Information Technology, p. A23.

Zhang, Y., Espinoza, S. (1998). Relationships among computer self-efficacy, attitudes toward computers, and desirability of learning computing skills. Journal of Research on Computing in Education, 30, 420-431. 
Appendix A - Survey

\section{Survey of Modeling and Requirements: Educational Technology Standards for Preservice Teachers}

Please circle the number that best represents the degree to which you:

Part I

General Preparation Standards

1. demonstrate a sound understanding of the nature and operation of technology systems.

2. demonstrate proficiency in the use of common input and output devices; solve routine hardware and software problems, and make informed choices about technology systems, resources, and services.

3. use technology tools and information resources to increase productivity, promote creativity, and facilitate academic learning.

4. use content-specific tools to support learning and research.

5. use technology resources to facilitate higher order and complex thinking skills, including problem solving, critical thinking, informed decision making, knowledge construction, and creativity.

6. collaborate in constructing technology-enhanced models, preparing publications, and producing other creative works using productivity tools.

7. use technology to locate, evaluate and collect information from a variety of sources.

8. use technology tools to process data and report results.

9. use technology in the development of strategies for solving problems in the real world.

10. observe and experience the use of technology in their major field of study.

11. use technology tools and resources for managing and communicating information.

12. evaluate and select new information resources and technological innovations based on their appropriateness to specific tasks.

13. use a variety of media and formats, including telecommunications, to collaborate, publish, and interact with peers, experts, and other audiences.

14. demonstrate an understanding of the legal, ethical, cultural and societal issues related to technology.
Model to students Require of students

Low High High
12345
12345

12345

12345

12345

12345

12345

12345

12345

12345

12345

12345

12345

12345

12345

12345

12345

12345

12345

12345

12345

12345

12345

12345

12345

12345

12345

12345 
Please circle the number that best represents the degree to which you:

\section{Standards}

15. exhibit positive attitudes toward technology uses that support lifelong learning, collaboration, personal pursuits, and productivity.

16. discuss diversity issues related to electronic media

17. discuss the health and safety issues related to technology use.

\section{Professional Preparation Standards}

18. identify the benefits of technology to maximize student learning and facilitate higher order thinking skills.

19. differentiate between appropriate and inappropriate uses of technology for teaching and learning while using electronic resources to design and implement learning activities.

20. identify technology resources available in schools and analyze how accessibility to those resources affects planning for instruction.

21. identify, select, and use hardware and software technology resources specially designed for use by PK-12 students to meet specific teaching and learning objectives.

22. plan for the management of electronic instructional resources within a lesson design by identifying potential problems and planning for solutions.

23. identify specific technology applications and resources that maximize student learning, address learner needs, and affirm diversity.

24. design and teach technology-enriched learning activities that connect content standards with student technology standards and meet the diverse needs of the students.

25. design and peer teach a lesson that meets content area standards and reflects the current best practices in teaching and learning with technology.

26. plan and teach student-centered learning activities and lessons in which students apply technology tools and resources.

27. research and evaluate the accuracy, relevance, appropriateness, comprehensiveness, and bias of electronic information resources to be us ed by students.
Model to students

Require of students

Low

High

Low

High

12345

12345

12345

12345

12345

12345
12345

12345

12345

12345

12345

12345

12345

12345

12345

12345

12345

12345

12345

12345

12345

12345

12345

12345

12345 
Please circle the number that best represents the degree to which you:

Model to students Require of students

Standards

Low

High

Low

High

28. discuss technology-based assessment

12345

12345

and evaluation strategies.

29. examine multiple strategies for evaluating technology-

12345

12345

based student products and the processes used to

create those products.

30. examine technology tools used to collect, analyze, interpret, represent, and communicate student performance data.

31. integrate technology-based assessment strategies and tools into plans for evaluating specific learning activities.

32. develop a portfolio of technology-based products from coursework, including the related assessment tools.

33. identify and engage in technology-based opportunities for professional education and lifelong learning, including the use of distance education.

34. apply online and other technology resources to support problem solving and related decision making for maximizing student learning

35. participate in online professional collaborations with peers and experts.

36. use technology productivity tools to complete required professional tasks.

37. identify technology-related legal and ethical issues, including copyright, privacy, and security of technology systems, data, and information.

38. examine acceptable use policies for the use of technology in schools, including strategies for addressing threats to security of technology systems, data, and information.

39. identify issues related to equitable access to environment.

40. identify safety and health issues related to technology use in schools.

41. identify and use assistive technologies to meet the special physical needs of students. 


\section{Part II}

\section{Background Information:}

A. What course(s) are you teaching?

B. How many years have you been teaching in an institution of higher education?

C. If applicable, how many years have you taught in $\mathrm{K}-12$ settings?

D. Does your college require students to conform to ISTE standards?

E. Overall, how would you rate your computer skills? (please circle the most appropriate word) novice beginner intermediate advanced expert

F. Have you noted any support for or obstacles to the integration of technology into your college courses? If so, what have you found?

Additional comments: 


\section{Appendix B - Instructions}

\section{Instructions for completion of the survey}

\section{Explanations:}

This survey is based directly on the International Society for Technology in Education standards for preservice teachers. The standards you will respond to on the following pages describe activities with which students should be familiar before they begin their major field work. It is understood that preservice students will gain experience with technology through many venues in various classes, through workshops, through peer activities and on their own.

It is expected that there will be some standards which particular faculty members do not model for their classes, and do not require of their students, since the standards are based on the students' entire schooling, not each class. Please view each standard in relation to your particular class(es) and your knowledge of student performance in those classes.

\section{Definitions:}

Degree - this survey uses a Likert-type scale, with one being low degree and five being high degree.

(low = fewer than one-tenth of the classes/semester, or a minor component of the course; high $=$ more than two-thirds of the classes/semester, or a major component of the course)

Faculty Modeling - directly using the technology in the class or in other venues in which students from those classes are present. (e.g. in meetings, conferences, workshops which the students attend).

Proficiency - students exhibit familiarity with the standard, either through using a particular technology or speaking knowledgeably about it.

Requiring - those activities which are part of class assignments or assignments from other venues for which the student is responsible to the faculty member.

Technology - for the purposes of this research, it refers to computer technology.

\section{Instructions:}

\section{Part I:}

There are two questions for each standard-

- to what degree do you model this standard to your students

- to what degree do you require your students exhibit proficiency in this standard

For each standard, please circle the number that best describes your response. (1=low, $5=$ high)

\section{Part II:}

There are six questions on the last page. Information gathered will be used to provide a broader understanding of the content questions. There is also an opportunity for you to offer comments. 


\section{Appendix C - Cover letter}




\section{West VirginiaUniversity}

\section{College of Human Resources and Education}

April 19, 2002

Dear Faculty Member:

I am a graduate student at West Virginia University completing my doctoral work in Technology Education under the supervision of Dr. George Maughan. I am writing to ask if you would be willing to participate in my doctoral research.

This research is intended to determine the relationship between education faculty perceptions of their teaching, and the activities they require of their students, and a set of technology standards for preservice students. In order to do this, I have developed a self-report survey, based on standards developed by the International Society for Technology in Education. The survey has been mailed to all full-time education faculty at schools in Vermont which certify students to teach in $\mathrm{K}-12$ settings.

I have enclosed a survey, which is the data-gathering instrument for my dissertation. You will also find a contrasting color sheet with explanations to assist you in the completion of the survey. I would appreciate it if you would take the time (approximately 15 minutes) to fill it out. Please return it, within two weeks, in the stamped, pre-addressed envelope. Your participation is entirely voluntary and you do not have to respond to every item or question. There will be initial tracking in order to ensure that unreturned surveys are not due to mismailings, but once the surveys have been returned your responses will remain anonymous and confidentiality will be maintained.

At the completion of my research, I would be happy to share the results with any participants who request that information. I expect that the data I gather will be of use to those who participated so they might compare their practices to others in the state. It will also add depth and breadth to the literature on the integration of technology into teacher education programs.

If you have any questions, please call me at 802-862-4945, or email me at rtwery@adelphia.net.

Thank you for your consideration.

Robin Twery

Ed.D. Candidate

Department of Advanced Educational Studies

Educational Leadership Studies, Educational Psychology,

Social and Cultural Foundations, Technology Education 


\section{Appendix D - Email Reminder}

\section{Dear Faculty Member}

On April 19th, I mailed a survey to education faculty across Vermont. It is the instrument I am using to gather data for my dissertation in Technology Education through West Virginia University. I am writing to you because, according to my records, you have not yet returned a completed survey.

Please let me know if:

You never received a copy of the survey so I can send you one now

You received it and

you have already returned it

you will be filling it out when the semester is over/grades are in

you no longer have it so I should send another copy

you prefer not to complete it

Thank you for your time

Robin Twery 


\section{Appendix E. Cover reminder for second mailing}

Dear Faculty Member:

On April $19^{\text {th }}$, I mailed a survey to education faculty across Vermont. It is the instrument I am using to gather data for my dissertation in Technology Education through West Virginia University. According to my records, I have not received your reply. Observing standard survey research procedures, I am enclosing a follow-up copy of the survey. Since the population for the survey is based on information which may be dated, please let me know if you are not currently teaching students so that I may adjust the population count.

Thank you for your consideration,

Robin Twery 


\section{Appendix F. Results of t-test and Pearson correlations - required vs. modeled}

\begin{tabular}{|l|l|l|l|l|l|}
\hline Standard & required mean & modeled mean & t-Ratio & p value & correlation \\
\hline 1 & 2.79688 & 2.89062 & -0.45444 & 0.6527 & $0.666 / 30^{\star}$ \\
\hline 2 & 2.40323 & 2.48387 & -0.4278 & 0.6718 & $0.713 / 29^{\star}$ \\
\hline 3 & 3.53125 & 3.6875 & -0.98983 & 0.3299 & $0.731 / 30^{\star}$ \\
\hline 4 & 3.16129 & 3.25806 & -0.5998 & 0.5531 & $0.765 / 29^{\star}$ \\
\hline 5 & 2.67742 & 2.85484 & -1.14641 & 0.2607 & $0.801 / 29^{\star}$ \\
\hline 6 & 2.98438 & 3.125 & -0.63522 & 0.5299 & $0.624 / 30^{\star}$ \\
\hline 7 & 3.96774 & 3.8871 & $0.595632^{\wedge}$ & 0.5559 & $0.797 / 29^{\star}$ \\
\hline 8 & 2.80645 & 2.95161 & -0.95257 & 0.3484 & $0.847 / 29^{\star}$ \\
\hline 9 & 2.58929 & 2.5 & $0.57808 \wedge$ & 0.5679 & $0.841 / 28^{\star}$ \\
\hline 10 & 3.46667 & 3.53333 & -0.3725 & 0.7122 & $0.779 / 28^{\star}$ \\
\hline 11 & 3.90625 & 4.01562 & -0.72039 & 0.4767 & $0.695 / 30^{\star}$ \\
\hline 12 & 2.81034 & 2.89655 & -0.61347 & 0.5445 & $0.864 / 27^{*}$ \\
\hline 13 & 3.06667 & 3.28333 & -1.18999 & 0.2437 & $0.792 / 28^{*}$ \\
\hline 14 & 3.05172 & 3.2069 & -1.0266 & 0.3134 & $0.828 / 27^{\star}$ \\
\hline 15 & 3.25 & 3.83333 & -3.24919 & $0.0029{ }^{\star *}$ & $0.77 / 28^{*}$ \\
\hline 16 & 2.75 & 2.7 & $0.593487^{\wedge}$ & 0.5575 & $0.946 / 28^{*}$ \\
\hline 17 & 2.0 & 2.0 & 0 & 1.0000 & $0.971 / 27^{*}$ \\
\hline 18 & 3.15 & 3.23333 & -0.70833 & 0.4844 & $0.887 / 30^{\star}$ \\
\hline 19 & 3.08621 & 3.05172 & $0.242154^{\wedge}$ & 0.8104 & $0.848 / 29^{\star}$ \\
\hline 20 & 3.16667 & 3.16667 & 0.0 & 1.0000 & $0.862 / 28^{\star}$ \\
\hline 21 & 3.0 & 2.88333 & $0.736315^{\wedge}$ & 0.4675 & $0.829 / 28^{\star}$ \\
\hline
\end{tabular}

${ }^{*} p<.05$, ^indicates required mean is greater than modeled mean. 


\section{Appendix F. Results of t-test and Pearson correlations - required vs. modeled, continued.}

\begin{tabular}{|l|l|l|l|l|l|}
\hline Standard & required mean & modeled mean & $t$ ratio & p value & correlation \\
\hline 22 & 2.75 & 2.53571 & $1.652373^{\wedge}$ & 0.1100 & $0.894 / 26^{\star}$ \\
\hline 23 & 2.83333 & 2.81481 & $0.13484^{\wedge}$ & 0.8938 & $0.876 / 25^{\star}$ \\
\hline 24 & 2.67857 & 2.48214 & $1.17384^{\wedge}$ & 0.8938 & $0.800 / 26^{\star}$ \\
\hline 25 & 2.33929 & 2.32143 & $1.121833^{\wedge}$ & 0.9039 & $0.849 / 26^{\star}$ \\
\hline 26 & 3.03704 & 2.72222 & $1.935397^{\wedge}$ & 0.0639 & $0.836 / 25^{\star}$ \\
\hline 27 & 2.74074 & 2.66667 & $0.527328^{\wedge}$ & 0.6024 & $0.903 / 25^{\star}$ \\
\hline 28 & 2.5 & 2.55357 & $-0.40589^{\star}$ & 0.6880 & $0.881 / 26^{\star}$ \\
\hline 29 & 2.22222 & 2.16667 & $0.549841^{\wedge}$ & 0.5871 & $0.919 / 25^{\star}$ \\
\hline 30 & 2.17308 & 2.25 & -0.49266 & 0.6265 & $0.845 / 26^{\star}$ \\
\hline 31 & 2.22222 & 2.11111 & $1.00000^{\wedge}$ & 0.3265 & $0.875 / 25^{\star}$ \\
\hline 32 & 2.375 & 2.28571 & $0.723084^{\wedge}$ & 0.4758 & $0.902 / 26^{\star}$ \\
\hline 33 & 2.37037 & 2.44444 & $-0.53711^{\wedge}$ & 0.5958 & $0.884 / 25$ \\
\hline 34 & 2.88889 & 2.87037 & $0.214328^{\wedge}$ & 0.8320 & $0.961 / 25^{\star}$ \\
\hline 35 & 2.75926 & 3.2963 & -2.38938 & $0.0244{ }^{\star}$ & $0.706 / 25^{\star}$ \\
\hline 36 & 3.09259 & 3.40741 & $-1.56041^{\star}$ & 0.1308 & $0.757 / 25^{\star}$ \\
\hline 37 & 3.21429 & 3.19643 & $0.146443^{\wedge}$ & 0.8847 & $0.903 / 26^{\star}$ \\
\hline 38 & 2.03846 & 2.07692 & $-0.44023^{\star}$ & 0.6636 & $0.960 / 24$ \\
\hline 39 & 2.53704 & 2.55556 & $-0.19641^{\star}$ & 0.8458 & $0.958 / 25^{\star}$ \\
\hline 40 & 2.11111 & 2.07407 & $0.464508^{\wedge}$ & 0.6462 & $0.955 / 25^{\star}$ \\
\hline 41 & 2.53571 & 2.44643 & $0.680181^{\wedge}$ & 0.5022 & $0.904 / 26^{\star}$ \\
\hline
\end{tabular}

${ }^{*} p<.05$, ^indicates required mean is greater than modeled mean. 
Appendix G. Pearson correlations for demographic questions by standards modeled

rate own skills $\quad$ years tch high $\quad$ yrs tch k12

\begin{tabular}{|c|c|c|c|c|c|c|}
\hline Standards & correlation & df & correlation & df & correlation & $\bar{d}$ \\
\hline 1 & $0.458^{*}$ & 30 & -0.251 & 30 & 0.271 & 30 \\
\hline 2 & $0.517^{\star}$ & 29 & -0.237 & 29 & $0.385^{\star}$ & 29 \\
\hline 3 & $0.521^{*}$ & 30 & -0.197 & 30 & 0.140 & 30 \\
\hline 4 & $0.553^{*}$ & 29 & -0.017 & 29 & -0.069 & 29 \\
\hline 5 & $0.532^{*}$ & 29 & -0.322 & 30 & $0.398^{*}$ & 29 \\
\hline 6 & $0.400^{*}$ & 30 & -0.250 & 30 & 0.188 & 30 \\
\hline 7 & $0.589^{\star}$ & 29 & -0.203 & 30 & 0.124 & 29 \\
\hline 8 & $0.610^{*}$ & 30 & -0.327 & 29 & 0.197 & 30 \\
\hline 9 & 0.359 & 26 & $-0.377^{*}$ & 30 & 0.315 & 26 \\
\hline 10 & 0.335 & 29 & -0.243 & 29 & 0.179 & 29 \\
\hline 11 & $0.379^{*}$ & 30 & -0.114 & 30 & -0.016 & 30 \\
\hline 12 & 0.353 & 28 & -0.077 & 28 & 0.208 & 28 \\
\hline 13 & 0.342 & 28 & -0.209 & 28 & 0.260 & 28 \\
\hline 14 & $0.581^{*}$ & 29 & -0.321 & 29 & $0.418^{*}$ & 29 \\
\hline 15 & 0.341 & 29 & -0.101 & 29 & 0.109 & 29 \\
\hline 16 & $0.370^{*}$ & 28 & -0.068 & 28 & 0.261 & 28 \\
\hline 17 & 0.136 & 27 & 0 & 27 & $0.359^{*}$ & 27 \\
\hline 18 & $0.462^{*}$ & 29 & -0.240 & 29 & 0.251 & 29 \\
\hline 19 & $0.373^{*}$ & 27 & -0.114 & 27 & 0.206 & 27 \\
\hline 20 & $0.367^{*}$ & 28 & -0.102 & 28 & 0.261 & 28 \\
\hline 21 & 0.229 & 28 & -0.201 & 28 & 0.236 & 28 \\
\hline
\end{tabular}

${ }^{*} p<.05$ 
Appendix G. Pearson correlations for demographic questions by standards modeled, continued.

rate own skills years tch high

yrs tch k12

\begin{tabular}{|l|l|l|l|l|l|l|}
\hline standard & correlation & df & correlation & df & correlation & df \\
\hline 22 & $0.601^{*}$ & 26 & -0.182 & 26 & 0.064 & 26 \\
\hline 23 & $0.606^{*}$ & 25 & -0.162 & 25 & 0.249 & 25 \\
\hline 24 & $0.530^{*}$ & 26 & -0.203 & 26 & 0.281 & 26 \\
\hline 25 & 0.300 & 26 & -0.249 & 26 & 0.211 & 26 \\
\hline 26 & $0.543^{*}$ & 25 & -0.122 & 25 & 0.154 & 25 \\
\hline 27 & $0.514^{*}$ & 25 & -0.348 & 25 & 0.389 & 25 \\
\hline 28 & 0.186 & 26 & -0.033 & 26 & 0.308 & 26 \\
\hline 29 & $0.400^{*}$ & 26 & 165 & 27 & 0.228 & 26 \\
\hline 30 & $0.606^{*}$ & 26 & -0.173 & 26 & 0.340 & 26 \\
\hline 31 & 0.353 & 26 & -0.266 & 26 & $0.408^{*}$ & 27 \\
\hline 32 & 0.324 & 26 & -0.234 & 26 & 0.119 & 26 \\
\hline 33 & $0.451^{*}$ & 25 & -0.074 & 25 & 0.214 & 26 \\
\hline 34 & $0.429^{*}$ & 26 & -0.081 & 26 & 0.061 & 26 \\
\hline 35 & $0.432^{*}$ & 26 & -0.271 & 26 & 0.303 & 26 \\
\hline 36 & $0.577^{*}$ & 27 & -0.013 & 27 & 0.081 & 27 \\
\hline 37 & $0.647^{*}$ & 26 & -0.326 & 26 & 0.329 & 26 \\
\hline 38 & $0.477^{*}$ & 24 & -0.381 & 24 & $0.443^{*}$ & 24 \\
\hline 39 & 0.300 & 26 & -0.163 & 27 & 0.224 & 26 \\
\hline 40 & 0.263 & 25 & -0.195 & 25 & 387 & 25 \\
\hline 41 & 0.206 & 26 & -0.168 & 23 & 0.238 & 26 \\
\hline & & & & & & \\
\hline
\end{tabular}

${ }^{*} p<.05$ 
Appendix H. Pearson correlations for demographic questions by standards required

\section{rate own skills $\quad$ years tch high $\quad$ yrs tch k12}

\begin{tabular}{|l|l|l|l|l|l|l|}
\hline Standards & correlation & df & correlation & df & correlation & df \\
\hline 1 & 0.190 & 30 & -0.315 & 30 & $0.360^{*}$ & 30 \\
\hline 2 & 0.276 & 29 & -0.349 & 29 & $0.349^{*}$ & 29 \\
\hline 3 & 0.285 & 30 & -0.143 & 29 & 0.227 & 30 \\
\hline 4 & $0.404^{*}$ & 29 & -0.042 & 29 & 0.037 & 29 \\
\hline 5 & 0.344 & 29 & -0.310 & 30 & $0.413^{*}$ & 30 \\
\hline 6 & 0.263 & 30 & $-0.413^{*}$ & 30 & $0.419^{*}$ & 30 \\
\hline 7 & $0.437^{*}$ & 29 & -0.217 & 30 & 0.142 & 30 \\
\hline 8 & $0.419^{\star}$ & 30 & -0.342 & 29 & $0.426^{*}$ & 29 \\
\hline 9 & 0.231 & 26 & -0.224 & 26 & 0.354 & 26 \\
\hline 10 & 0.152 & 29 & $-0.408^{*}$ & 28 & 0.283 & 28 \\
\hline 11 & 0.327 & 30 & -0.149 & 30 & 0.076 & 30 \\
\hline 12 & 0.195 & 28 & -0.066 & 27 & 0.263 & 27 \\
\hline 13 & 0.234 & 28 & -0.198 & 28 & 0.322 & 28 \\
\hline 14 & 0.323 & 29 & -0.285 & 27 & $0.375^{*}$ & 27 \\
\hline 15 & 0.137 & 29 & -0.120 & 28 & 0.279 & 28 \\
\hline 16 & 0.320 & 28 & -0.125 & 28 & $0.363^{*}$ & 28 \\
\hline 17 & 0.663 & 27 & -0010 & 28 & $0.387^{*}$ & 27 \\
\hline 18 & 0.303 & 29 & $-0.371^{*}$ & 28 & $0.369^{*}$ & 28 \\
\hline 19 & 0.214 & 27 & $-0.388^{*}$ & 27 & $0.387^{*}$ & 27 \\
\hline 20 & 0.162 & 28 & -0.227 & 28 & 0.298 & 28 \\
\hline 21 & 0.065 & 28 & -0.354 & 28 & $0.464^{*}$ & 28 \\
\hline
\end{tabular}

${ }^{*} p<.05$ 
Appendix H. Pearson correlations for demographic questions by standards required, continued.

rate own skills $\quad$ years tch high $\quad$ yrs tch k12

\begin{tabular}{|l|l|l|l|l|l|l|}
\hline standard & correlation & \multicolumn{1}{|c|}{ df } & correlation & df & correlation & df \\
\hline 22 & $0.452^{*}$ & 26 & -0.228 & 26 & 0.204 & 26 \\
\hline 23 & $0.421^{*}$ & 25 & -0.252 & 25 & 0.332 & 25 \\
\hline 24 & 0.280 & 26 & -0.331 & 26 & $0.450^{*}$ & 26 \\
\hline 25 & 0.066 & 26 & -0.288 & 26 & 0.173 & 26 \\
\hline 26 & 0.317 & 25 & -0.221 & 25 & 0.263 & 25 \\
\hline 27 & $0.428^{*}$ & 25 & $-0.414^{*}$ & 25 & $0.505^{*}$ & 25 \\
\hline 28 & 0.040 & 26 & -0.243 & 26 & $0.463^{*}$ & 26 \\
\hline 29 & 0.304 & 25 & -0.347 & 25 & $0.393^{*}$ & 25 \\
\hline 30 & 0.352 & 24 & -0.186 & 24 & $0.479^{*}$ & 24 \\
\hline 31 & 0.127 & 25 & -0.297 & 25 & $0.484^{*}$ & 25 \\
\hline 32 & 0.219 & 26 & -0.196 & 26 & 0.227 & 26 \\
\hline 33 & 0.349 & 25 & -0.238 & 25 & $0.431^{*}$ & 25 \\
\hline 34 & 0.376 & 25 & -0.164 & 25 & 0.170 & 25 \\
\hline 35 & 0.181 & 25 & -0.242 & 25 & 0.346 & 25 \\
\hline 36 & $0.414^{\star}$ & 25 & -0.146 & 25 & 0.278 & 25 \\
\hline 37 & $0.470^{*}$ & 26 & $-0.363^{*}$ & 26 & 0.286 & 26 \\
\hline 38 & $0.415^{\star}$ & 24 & -0.336 & 24 & 0.371 & 24 \\
\hline 39 & 0.234 & 25 & -0.171 & 25 & 0.233 & 25 \\
\hline 40 & 0.168 & 25 & -0.244 & 25 & $0.452^{*}$ & 25 \\
\hline 41 & 0.067 & 26 & -0.200 & 26 & 0.291 & 26 \\
\hline & & & & & & \\
\hline
\end{tabular}

$* p<.05$ 
Appendix I. Contingency table significance for standards modeled by demographics

\begin{tabular}{|c|c|c|c|}
\hline standard & $\begin{array}{l}\text { State/priv } \\
\text { university }\end{array}$ & $\begin{array}{l}\text { College- } \\
\text { small/big }\end{array}$ & $\begin{array}{l}\text { ISTE } \\
\text { req. }\end{array}$ \\
\hline 1 & 0.9449 & 0.8746 & 0.5812 \\
\hline 2 & 0.1958 & 0.6482 & 0.0199 * \\
\hline 3 & 0.5668 & 1.0000 & 0.3142 \\
\hline 4 & 0.3896 & 0.2049 & 0.0742 \\
\hline 5 & 0.3358 & 0.3583 & 0.0571 \\
\hline 6 & 0.1310 & 0.1619 & 0.3060 \\
\hline 7 & 0.9209 & 0.6437 & 0.7016 \\
\hline 8 & 0.0580 & 0.1390 & 0.9153 \\
\hline 9 & 0.1589 & 0.1504 & 0.6176 \\
\hline 10 & 0.8960 & 0.8331 & 0.1292 \\
\hline 11 & 0.5765 & 0.4901 & 0.1701 \\
\hline 12 & 0.4760 & 0.5110 & $0.0247^{*}$ \\
\hline 13 & 0.0789 & 0.2709 & 0.0971 \\
\hline 14 & 0.7204 & 0.0111 & 0.3583 \\
\hline 15 & 0.1470 & 0.0904 & 0.5429 \\
\hline 16 & 0.0146 * & 0.5466 & 0.8356 \\
\hline 17 & 0.0440 & 0.0327 & 0.1327 \\
\hline 18 & 0.5823 & 0.8697 & 0.0620 \\
\hline 19 & 0.4823 & 0.3518 & 0.0439 * \\
\hline 20 & 0.2276 & 0.5476 & 0.1995 \\
\hline 21 & 0.5555 & 0.3052 & 0.3949 \\
\hline
\end{tabular}

${ }^{*} p<.05$ 


\section{Appendix I. Contingency table significance for standards modeled by demographics, continued}

\begin{tabular}{|c|c|c|c|}
\hline standard & $\begin{array}{l}\text { State/priv } \\
\text { university }\end{array}$ & $\begin{array}{l}\text { College- } \\
\text { small/big }\end{array}$ & $\begin{array}{l}\text { ISTE } \\
\text { req. }\end{array}$ \\
\hline 22 & 0.3690 & 0.0048 * & 0.1493 \\
\hline 23 & 0.9613 & 0.8383 & 0.0206 * \\
\hline 24 & 0.0914 & 0.0377 * & 0.2256 \\
\hline 25 & 0.6026 & 0.5753 & 0.3943 \\
\hline 26 & 0.2586 & 0.8640 & 0.1834 \\
\hline 27 & 0.7132 & 0.9853 & 0.1359 \\
\hline 28 & 0.1343 & 0.2348 & 0.2643 \\
\hline 29 & 0.5407 & 0.5022 & 0.1727 \\
\hline 30 & 0.3956 & 0.3086 & 0.2567 \\
\hline 31 & 0.6011 & 0.5356 & 0.1126 \\
\hline 32 & 0.1594 & 0.0460 * & 0.2571 \\
\hline 33 & 0.0644 & 0.4008 & 0.3439 \\
\hline 34 & 0.1792 & 0.0622 & 0.4816 \\
\hline 35 & 0.1621 & 0.0706 & 0.1482 \\
\hline 36 & 0.6427 & 0.9200 & 0.0438 * \\
\hline 37 & 0.4334 & 0.3083 & 0.0590 \\
\hline 38 & 0.5462 & 0.2700 & 0.0950 \\
\hline 39 & 0.1467 & 0.4441 & 0.6603 \\
\hline 40 & 0.1590 & 0.9482 & 0.2567 \\
\hline 41 & 0.5927 & 0.3098 & 0.6176 \\
\hline
\end{tabular}

${ }^{*} p<.05$ 
Appendix J. Contingency table of significance - standards required by demographics

\begin{tabular}{|c|c|c|c|}
\hline Standard & $\begin{array}{l}\text { State/priv } \\
\text { university }\end{array}$ & $\begin{array}{l}\text { College- } \\
\text { small/big }\end{array}$ & $\begin{array}{l}\text { ISTE } \\
\text { req }\end{array}$ \\
\hline 1 & 0.5008 & 0.8894 & 0.1292 \\
\hline 2 & 0.1003 & 0.4433 & 0.0697 \\
\hline 3 & 0.9700 & 0.7651 & 0.4199 \\
\hline 4 & 0.7344 & 0.6615 & 0.0376 * \\
\hline 5 & 0.9654 & 0.8894 & 0.3128 \\
\hline 6 & 0.6300 & 0.8894 & 0.1865 \\
\hline 7 & 0.8008 & 0.5452 & 0.4622 \\
\hline 8 & 0.1519 & 0.0788 & 0.1184 \\
\hline 9 & 0.0184 & 0.0249 * & 0.0894 \\
\hline 10 & 0.5459 & 0.3177 & 0.0722 \\
\hline 11 & 0.3834 & 0.5878 & 0.1596 \\
\hline 12 & 0.4678 & 0.4786 & 0.4903 \\
\hline 13 & 0.1969 & 0.5177 & 0.0219 * \\
\hline 14 & 0.5017 & 0.3456 & 0.5599 \\
\hline 15 & 0.2100 & 0.6513 & 0.1814 \\
\hline 16 & 0.0054 & 0.1754 & 0.5007 \\
\hline 17 & 0.0442 & 0.0327 * & 0.0542 * \\
\hline 18 & 0.3636 & 0.8640 & 0.1936 \\
\hline 19 & 0.6048 & 0.8619 & 0.4390 \\
\hline 20 & 0.9285 & 0.8804 & 0.5369 \\
\hline 21 & 0.4486 & 0.9194 & 0.6140 \\
\hline
\end{tabular}

${ }^{*} p<.05$ 
Appendix J. Contingency table of significance - standards required by demographics, continued.

\begin{tabular}{|c|c|c|c|}
\hline standard & $\begin{array}{l}\text { State/priv } \\
\text { university }\end{array}$ & $\begin{array}{l}\text { College- } \\
\text { small/big }\end{array}$ & $\begin{array}{l}\text { ISTE } \\
\text { req. }\end{array}$ \\
\hline 22 & 0.5581 & 0.9194 & 0.5557 \\
\hline 23 & 0.3468 & 0.2454 & 0.0668 \\
\hline 24 & 0.0809 & 0.4236 & $0.0155^{*}$ \\
\hline 25 & 0.2863 & 0.5262 & 0.6664 \\
\hline 26 & 0.2750 & 0.8153 & 0.1850 \\
\hline 27 & 0.6123 & 0.7447 & 0.0165 * \\
\hline 28 & $0.0271 *$ & 0.1522 & 0.5767 \\
\hline 29 & 0.7430 & 0.3817 & 0.3994 \\
\hline 30 & 0.4448 & 0.3287 & 0.0948 \\
\hline 31 & 0.5214 & 0.4947 & 0.0224 * \\
\hline 32 & 0.1400 & 0.0657 & 0.1532 \\
\hline 33 & 0.2842 & 0.3956 & 0.0801 \\
\hline 34 & 0.1342 & 0.0372 * & 0.1726 \\
\hline 35 & 0.0068 * & 0.0148 * & 0.0095 * \\
\hline 36 & 0.0305 * & 0.3764 & 0.2639 \\
\hline 37 & 0.6060 & 0.4729 & 0.0356 * \\
\hline 38 & 0.7569 & 0.8240 & 0.2877 \\
\hline 39 & 0.0463 * & 0.2013 & 0.9240 \\
\hline 40 & 0.0708 & 0.3412 & 0.0224 * \\
\hline$\overline{41}$ & 0.2193 & 0.2021 & 0.4736 \\
\hline
\end{tabular}

${ }^{*} \mathrm{p}<.05$ 


\section{Appendix K. Pearson Correlations for Demographic Questions by Categories}

Categories

\begin{tabular}{|c|c|c|c|c|c|c|}
\hline Demographic Questions & $\mathrm{I}$ & II & III & IV & $\mathrm{V}$ & $\mathrm{VI}$ \\
\hline \multicolumn{7}{|l|}{ rate own skills } \\
\hline modeled/general & $0.577 / 30^{*}$ & |-------- & $0.551 / 30^{*}$ & $0.634 / 28^{*}$ & $0.543 / 29^{*}$ & $0.476 / 29^{*}$ \\
\hline modeled/professional & $0.561 / 29^{*}$ & $0.480 / 29^{*}$ & $0.554 / 29^{*}$ & $0.540 / 27^{\star}$ & $0.598 / 29^{*}$ & $0.493 / 29^{*}$ \\
\hline required/general & $0.367 / 30^{*}$ & |-------- & $0.335 / 30$ & $0.398 / 30^{*}$ & $0.340 / 30$ & $0.268 / 28$ \\
\hline required/professional & $0.207 / 28$ & $0.248 / 29$ & $0.301 / 29$ & $0.324 / 29$ & $0.389 / 29^{*}$ & $0.307 / 29$ \\
\hline \multicolumn{7}{|l|}{ yrs tching higher ed } \\
\hline modeled/general & $-0.264 / 30$ & -- & $-0.279 / 30$ & $\mid-0.247 / 30$ & $-0.247 / 30$ & $-0.139 / 29$ \\
\hline modeled/professional & $-0.219 / 29$ & \begin{tabular}{|l|}
$-0.226 / 29$ \\
\end{tabular} & $-0.236 / 29$ & $-0.213 / 27$ & $-0.209 / 29$ & $-0.294 / 29$ \\
\hline required/general & $-0.280 / 30$ & $\mid----------$ & $-0.276 / 30$ & $-0.244 / 30$ & $-0.273 / 30$ & $-0.185 / 30$ \\
\hline required/professional & $-0.357 / 28^{*}$ & $-0.373 / 29^{\star}$ & $-0.353 / 29^{*}$ & $-0.319 / 27$ & $-0.324 / 29$ & $-0.399 / 29^{\star}$ \\
\hline \multicolumn{7}{|l|}{ yrs tching K-12 } \\
\hline modeled/general & $0.310 / 31$ & \begin{tabular}{|l|}
---------- \\
\end{tabular} & $0.232 / 30$ & $0.198 / 30$ & $0.201 / 30$ & $0.366 / 29^{*}$ \\
\hline modeled/professional & $0.244 / 30$ & $0.255 / 31$ & $-0.236 / 29$ & $0.355 / 27$ & $0.242 / 29$ & $0.335 / 29$ \\
\hline required/general & $0.361 / 30^{\star}$ & \begin{tabular}{|l}
---------- \\
\end{tabular} & $0.362 / 30^{*}$ & $0.334 / 30$ & $0.340 / 30$ & $0.334 / 30$ \\
\hline required/professional & $0.452 / 28^{*}$ & $0.374 / 29^{*}$ & $0.328 / 29$ & $0.482 / 27^{\star}$ & $0.353 / 29^{*}$ & $0.380 / 29^{*}$ \\
\hline
\end{tabular}

Note. General includes standards $1-17$, professional includes standards $18-41$; I is technology operations and concepts, II is planning and designing learning environments and experiences, III is teaching, learning and the curriculum, IV is assessment and evaluation, $\mathrm{V}$ is productivity and professional practice, and $\mathrm{VI}$ is social, ethical, legal, and human issues. ${ }^{*} p<.05$ 


\section{Appendix L . Contingency Tables of Demographic Questions by Categories}

Categories

\begin{tabular}{|c|c|c|c|c|c|c|}
\hline Demographic Questions & $\mathrm{I}$ & II & III & IV & $\mathrm{V}$ & $\mathrm{VI}$ \\
\hline \multicolumn{7}{|l|}{ college-state/private/u. } \\
\hline modeled/general & .1123 & & .1752 & .3467 & .3385 & $.0251^{*}$ \\
\hline modeled/professional & .4717 & .3337 & .4860 & .5136 & .5383 & .2129 \\
\hline required/general & .1928 & & .1632 & .1365 & .2464 & $.0195^{\star}$ \\
\hline required/professional & .5480 & $.0216^{*}$ & .5376 & .1724 & $.0296^{\star}$ & .2075 \\
\hline \multicolumn{7}{|l|}{ college-small/big } \\
\hline modeled/general & .3380 & & .2864 & .3470 & .4845 & .2157 \\
\hline modeled/professional & .3359 & .4748 & .2087 & .2641 & .4342 & .4060 \\
\hline required/general & .2230 & & .5466 & .7651 & .2147 & 1.0000 \\
\hline required/professional & .4836 & .6398 & .3479 & .1427 & .0563 & $.0459^{\star}$ \\
\hline \multicolumn{7}{|l|}{ ISTE standards required } \\
\hline modeled/general & .4608 & & .7326 & .6625 & .3898 & .2909 \\
\hline modeled/professional & .2125 & .1876 & .3534 & .1215 & $.0496^{*}$ & .0957 \\
\hline required/general & .1540 & & .6335 & .0934 & .2617 & .2690 \\
\hline required/professional & .4123 & .3601 & .2702 & $.0516^{*}$ & .2343 & .3041 \\
\hline
\end{tabular}

Note. General includes standards 1-17, professional includes standards 18-41; I is technology operations and concepts, II is planning and designing learning environments and experiences, III is teaching, learning and the curriculum, IV is assessment and evaluation, $\mathrm{V}$ is productivity and professional practice, and $\mathrm{VI}$ is social, ethical, legal, and human issues. ${ }^{*} \mathrm{p}<.05$ 


\title{
Curriculum Vitae
}

\author{
Robin T. Twery \\ 348 Appletree Point Road \\ Burlington, VT 05401 \\ (802) 862-4945 \\ rtwery@adelphia.net
}

\section{EDUCATION:}

Ed.D., Technology Education, West Virginia University, 2003

M.A., Learning Disabilities, University of Northern Colorado, 1974

Professional Certification, Elementary Education, University of Denver, 1973

B.A., Philosophy, Rutgers, the State University, 1971

\section{PROFESSIONAL EXPERIENCE:}

Special Education Teacher Milton Elementary School, Milton, VT. 1999-2000

Developed and implemented programs for second and third grade special education and title one students. Programs were based on existing and ongoing assessments of academic potential and achievement. Worked both in a resource setting and in regular education classrooms.

Coordinated services with various professionals including teachers and teaching assistants.

Special Education Substitute, Long Term Position

J.J. Flynn Elementary School, Burlington, VT. September-November 1998

Implemented program of special education for fourth and fifth grade students. The tasks included teaching small groups in class and in the Basic Skills room, testing new and continuing students, meeting with teachers, parents, and outside staff, and participating in afternoon and evening activities.

Educational Evaluator/Test Administrator

Educational Assessment Services, Burlington, VT. 1997-1998

Performed contracted testing of school-age children. Administered the Woodcock-Johnson Psychoeducational Battery to elementary, middle and high school students in the South Burlington School District. Coordinated with Special Education Teachers regarding testing decisions.

Supervisor, Student Teachers

Curriculum and Instruction, West Virginia University, Morgantown, WV. Fall 1994

Supervised pre-service students in the field; coordinated student's assignments with teaching staff; assisted university faculty in assessing student performance; completed observations and conferences with students and cooperating teachers; developed computer-based tutorial for new employees; completed reports on each student for permanent files.

\section{Research Instructor}

Research and Training Center, Morgantown, WV. 1989-1993

Assisted in the completion of research projects related to rehabilitation professionals and computer use. Work included literature searching using on-line and CD-ROM databases, interviewing vocational rehabilitation professionals regarding data needs and current agency linkages, and developing surveys to assess computer use in the field and job skills needed now and in the future. Also managed an in-house database for articles found through literature searches, and coordinated software distribution for an agency-developed jobs package. 
Resource Room Teacher

New Haven Public Schools, CT. 1986-1988

Developed and implemented individual academic programs for special needs students; coordinated and chaired Individual Education Plan meetings for the school, which included teachers, couns elors, parents and outside professionals; supervised all Educational Plans, and wrote those for my own students.

Vocational Evaluator/Test Administrator

The Rehab Center, New Haven, CT. 1985-1986

Administered work samples, paper, and computer tests to adult clients seeking vocational rehabilitation services; evaluated needs of clients and recommended placements; conducted conferences with clients and other service providers.

Resource Room Teacher

Gateway Regional Middle/High Schools, Huntington, MA. 1983-1984

Developed and implemented individual academic and work-study programs for special needs students; coordinated Individual Education Plan meetings; wrote Individual Education Plans for academic and vocational programs; monitored instructional aide.

\section{Curriculum Coordinator}

Northampton Center for Children and Families, Northampton, MA. 1980-1981

In a one year grant position, developed language arts and math curricula for grades

$\mathrm{K}-12$; assessed and selected basic and alternative educational materials and approaches; developed a format for students' intake from and return to public schools.

\section{High School English Teacher}

Northampton Center for Families and Children, Northampton, MA. 1979-1980

Created and used individualized curricula for remedial and advances students; tested and evaluated students; participated in preparation and implementation of quarterly and yearly plans, with both educational and behavioral objectives.

\section{Resource Room Teacher}

Boston Public Schools, Elementary and Middle grades, Boston, MA. 1976-1979

Developed and implemented individual academic programs for special needs students; attended Individual Education Plan meetings; wrote Individual Education Plans for academic programs; monitored instructional aide; developed and edited newsletter for Resource Room Programs throughout the city. 